\title{
Sin un lugar para pernoctar en "la garganta de Tierra Adentro". Los mesones en San Luis Potosí
}

\author{
José Armando Hernández Soubervielle \\ EL COLEGIO DE SAN LUIS
}

Ya sea por falta de fuentes primarias o por su escasa existencia, uno de los temas que ha recibido poco tratamiento académico es el que corresponde a la historia y análisis de los mesones en lo que fue el septentrión novohispano durante los siglos XVII y XVIII. El presente artículo tiene como finalidad hacer un análisis de las causas que llevaron a que se tengan muy pocas noticias acerca de esta tipología arquitectónica en lo que fue el San Luis Potosí virreinal, sobre todo considerando que el territorio era conocido como "la garganta de la Tierra Adentro", y por tanto, punto obligado de tránsito hacia el norte de Nueva Espańa. Al mismo tiempo se presentan por primera vez los datos que revelan la presencia de algunos mesones en la localidad en el siglo xviII, así como su análisis espacial. Se da cuenta de sus dueños así como de sus ubicaciones, además de darles un seguimiento resumido de su historia hasta principios del siglo XIX.

(Mesones, camino real de Tierra Adentro, San Luis Potosí, Septentrión novohispano)

uando tratamos de poner en perspectiva la fisonomía de lugares como San Luis Potosí en las postrimerías del siglo XVI y la primera mitad del XVII, imaginamos, además de un real de minas, un lugar de paso para la Tierra Adentro y otras regiones que conectaban el sur con el septentrión novohispano; ${ }^{1}$ es decir,

*ahernandez@colsan.edu.mx

${ }^{1}$ Rutas las había muchas desde muy temprano en la fundación del pueblo de San Luis Potosí: Desde San Luis hacia el norte se iba al importante real minero de Guadalcázar (fundado en 1615) y mucho más al norte, el camino hacia las Texas, pasando por Venado, Charcas (1574) y Matehuala (1600). Hacia el sur se conectaba con Querétaro, San Juan del Río y México pasando por San Luis de la Paz y San Miguel. Hacia el po- 
un punto que habría de convertirse, desde muy temprano, en una conexión geográfica obligada, tal como lo sigue siendo en nuestros días. A esta idea inicial debemos sumarle que como casi cualquier población que había nacido bajo el cobijo de la actividad minera, San Luis Potosí se vio imbuido desde su fundación en una febril actividad comercial regional debido al tráfico de los minerales extraídos y del constante avituallamiento de maíz, harina y otros géneros que recibía el pueblo de las regiones cercanas, conformando de esta manera una serie de factores que no pueden entenderse por separado, sino que, tal y como lo establece Florescano, funcionaban como el complejo real minero-hacienda-centro de abasto, donde quedaba manifiesta "la interdependencia económica entre la comunidad minera, la hacienda agrícola y los centros productores geográficamente próximos". ${ }^{2}$ Esta realidad implicaba en consecuencia el constante ingreso y egreso de carreteros y arrieros con sus bestias de carga, así como de personas que venían a San Luis por muy diversas causas, algunas de las cuales ocupaban de pasar largas estancias en el pueblo. Este trajín de personas con sus carros y animales hacían necesario que el pueblo ${ }^{3}$ contara con espacios para alojarse y resguardar sus bestias y mercancías; es decir, la necesidad de contar con mesones.

No obstante esta realidad, la bibliografía que trata sobre San Luis Potosí carece de trabajos que aborden y profundicen respecto a los mesones y su importancia durante el periodo virreinal, enfocándose los pocos existentes en tratar el tema del servicio de hospedería a partir del siglo XIX. Dos son las razones que justifican la ausencia de historiografía que trate, para el caso de San Luis Potosí, el tema de los mesones durante los siglos XVI, XVII y XVIII. La primera de ellas es que en cierta medida se le ha restado importancia al estudio de esta

niente Zacatecas pasando por San Miguel Mexquitic (1588) y las salinas del Peñol Blanco (1562), conectándose así con el Camino Real de Tierra Adentro. También hacia el poniente, Pinos, Ojuelos y la Nueva Galicia. Hacia el oriente, Rioverde (1617), Valle del Maíz (1617), Santiago de los Valles Oxitipa (1533) y más allá, Pánuco.

${ }^{2}$ Enrique Florescano, "El abasto y la legislación de granos en el siglo Xvı", en Historia Mexicana, vol. xIv, abril-junio de 1965, 590.

${ }^{3} \mathrm{Y}$ a partir de 1656 , ciudad. 
tipología arquitectónica de servicio público porque la información no es evidente ni está a la mano; la segunda, porque hasta el momento se ha considerado que a lo largo de estos siglos, en San Luis Potosí simplemente no existieron tales establecimientos, aun cuando éstos fueron fundamentales para consolidar el crecimiento de las poblaciones urbanas al albergar gran cantidad de viajeros a su llegada a las nuevas fundaciones.

Este segundo razonamiento no está exento de verdad para el caso potosino, más no en su totalidad. Lo cierto es que la información que hemos podido rescatar de archivo menciona apenas un par de mesones en la ciudad a finales del siglo xvin, pero al menos en uno de los casos lo hace con tal riqueza que a lo largo de este trabajo habremos incluso de proponer una reconstrucción hipotética de él.

Dos son también los factores que harían necesaria la existencia de mesones en San Luis Potosí, es el primero de ellos, como ya se insinuó, la minería. El constante flujo de mineral durante las postrimerías del siglo XVI y principios del XVII, procedente de las minas de la jurisdicción hacia San Luis Potosí - para que allí se ensayara y quintara-, y su posterior envío a México, implicaba la necesidad de un espacio para que los arrieros encargados pernoctaran junto con sus bestias. Ahora bien, si consideramos que el pueblo de San Luis estuvo compuesto en sus alrededores por haciendas de beneficio de metales, ${ }^{4}$ resulta válido pensar que la necesidad de aposento y corral se podía cubrir sin que fuese necesario contar con un establecimiento destinado exclusivamente para tal fin-como veremos sucedió en realidad-ya que las propias haciendas podían dar cobijo a los transportistas, o incluso a viajeros que nada tenían que ver con la hacienda y sus trabajos. ${ }^{5}$ A esta realidad debemos agregar que la minería durante estos primeros años fluctuó de tal forma que presentó una

${ }^{4}$ Isabel Monroy Castillo y Tomás Calvillo Unna, Breve historia de San Luis Potosí, México, FCE, El Colegio de México, 2000, 97.

${ }^{5}$ Esto era lo que pasaba, por ejemplo, en Parral, donde "los viajeros no tenían más remedio que alojarse en las haciendas, conventos o misiones de la región". Chantal Cramaussel, Poblar la frontera. La provincia de Santa Bárbara en Nueva Vizcaya durante los siglos XVI y XVII, Zamora, El Colegio de Michoacán, 2006, 118. 
serie de momentos críticos, ${ }^{6}$ que hicieron que bajara considerablemente su producción, generando en consecuencia una inestabilidad e inconsistencia en el ingreso y egreso de personas al pueblo ligadas a la minería.

Sin embargo, más importante que el factor de la minería, para justificar la existencia de un mesón en San Luis Potosí desde sus ańos fundacionales, es la necesidad de abastecimiento que se tenía (tanto para el pueblo, como para las minas referidas), lo que implicó desde muy temprano el ingreso de arrieros que transportaban el avituallamiento que el pueblo necesitaba. Muy pronto hubo de establecerse un centro de abasto para San Luis Potosí, un traspatio ${ }^{7}$ a través del cual el pueblo se haría con el maíz, las frutas, legumbres y demás mercaderías necesarias para la subsistencia.

En 1612, tenemos una de las primeras noticias acerca de la procedencia de algunos productos que llegaban al pueblo de San Luis. $\mathrm{Al}$ respecto se menciona que tanto en la villa de San Miguel como en la de San Felipe, existían unas haciendas de labor "muy gruesas" de "donde se cogía gran suma de maíz y otras legumbres que acostumbraba(n) enviar a vender a las minas de San Luis", y que lo mismo acudían con sus cosechas a este pueblo los labradores de los Llanos de Silao como los de otras regiones circunvecinas, para distribuir y vender sus maíces. ${ }^{8}$ Algunos años después, gracias a un recurso interpuesto en 1623 ante la Real Audiencia por el teniente capitán general de las fronteras chichimecas, don Juan Cerezo Salamanca, relativo a la saca de maíces de la Nueva Espańa rumbo a la Nueva Galicia (en particular a Zacatecas, Ramos y Sierra de Pinos), nos enteramos que desde la fundación del pueblo y minas de San Luis, tanto Silao, Celaya, San Miguel, San Felipe, así como la Congregación de Irapuato, habían sido constituidos por mandato real en lo que pudiéramos llamar el Hinterland ${ }^{9}$ de San Luis Potosí, te-

${ }^{6}$ Monroy Castillo, Breve historia de San Luis... Véase en particular el capítulo "Altibajos de la minería”.

${ }^{7}$ Como la mayoría de las fundaciones mineras, San Luis Potosí no contaba con buenas zonas de cultivo, lo que hacía necesario avituallarse de otros centros.

${ }^{8}$ AHESLP, Alcaldia Mayor, 1612.5 (caja 148), exp. 6, f. 1v. Octubre 3 de 1612.

${ }^{9}$ Este término, acuñado en 1888 por George Chisholm en su obra Handbook of 
niendo entre sus prohibiciones sacar maíz hacia lo que era la Nueva Galicia. ${ }^{10}$ Para hacer cumplir este mandato, el virrey Diego Carrillo de Mendoza y Pimentel, marqués de Gelves y conde de Priego, permitió se estableciera una patrulla para vigilar los caminos, lo que derivó muy pronto en el arresto de arrieros con recuas cargadas de maíz que, sorteando San Luis Potosí y otros puntos legales, pasaban el cereal procedente de San Miguel, San Felipe, Querétaro y Celaya con rumbo a Zacatecas. ${ }^{11}$ Estas referencias confirman que como todo importante real de minas a principios del siglo XVII, San Luis Potosí poseía una zona de abasto de cereal que coincidía con los caminos (principalmente de carreta) y presidios que se habían formado previa la fundación potosina en el siglo xvi (figura 1), ${ }^{12}$ cuya zona de influencia agrícola se concentraba en lo que ahora conocemos como la región del Bajío, ${ }^{13}$ que abastecía los centros mineros de Guanajuato, Comanjá y Pozos. ${ }^{14}$

Aunque en relación con el abastecimiento de maíz y harina las leyes eran muy precisas y concretas sobre quién abastecía a quién (lo cual desde la perspectiva de la logística y el control resultaba muy entendible), esto no obstaba para que de latitudes muy diversas, e incluso lejanas, los arrieros con sus recuas cargadas llegaran a las minas de San Luis para expender en el pueblo sus mercancías y avíos, ${ }^{15}$

Commercial Geography, sirve para designar las tierras que rodean una ciudad o zona de la cual ésta puede abastecerse.

${ }^{10}$ AHESlp, Alcaldía Mayor, 1623.3 (caja 206), exp. 16, f. 1rv. Marzo 6 de 1623. Ahora bien, en algún momento del siglo XvII esto cambió, ya que, aun siendo un abasto secundario, desde Irapuato se llevaba grano a la Nueva Galicia, pasando por los Altos y la región de Guadalajara (véase Thomas Calvo, Por los caminos de Nueva Galicia. Transportes y transportistas en el siglo XVII, Universidad de Guadalajara, Centre Français D'Études Mexicaines et Centraméricaines, México, 1997, 128).

${ }^{11}$ AHESLP, Alcaldía Mayor, 1623.3 (caja 206), exp. 16, ff. 3r-4v. Julio de 1623. Lo interesante de esto es que tanto los maíces como las recuas confiscadas, iban a parar inevitablemente a San Luis Potosí.

${ }^{12}$ La similitud de la forma de la zona de abasto con la de los caminos existentes validan la existencia del Hinterland potosino.

${ }^{13}$ Véase el cuadro de presidios fundados en el siglo xvi en Luis Arnal Simón, El presidio en México en el siglo XVI, Facultad de Arquitectura, México, UnAm, 1998, 41, figura 2 ; 45; 48, cuadro $1 ; 153$, cuadro 9; 179 , figura $41 ;$ y 182-83.

${ }^{14}$ Ibidem, p. 44.

${ }^{15}$ Sabemos, por ejemplo, que desde muy temprano se traían mercancías tan diversas 
Figura 1. Zona de abastecimiento de cereal, carne y fruta de la región en San Luis Potosí, primera mitad del siglo Xvir. Las rutas se han tomado de: Luis Arnal, El presidio en México en el siglo XVI, fig. 41

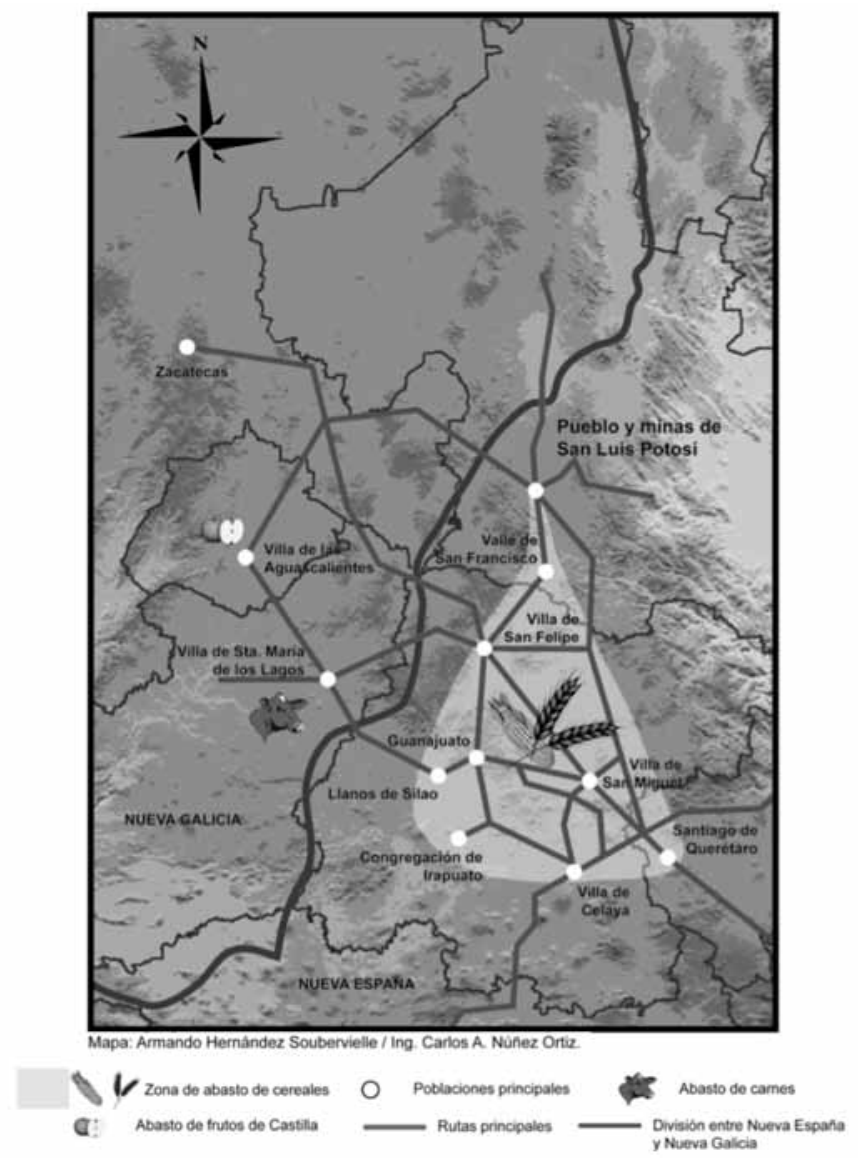

como plátanos verdes de Michoacán. AHEsLP, Alcaldía Mayor, 1620.8 (caja 191), exp. 30, ff. 1r-3v. Diciembre 19 de 1620. También hubieron de venderse en el pueblo otro tipo de artículos como lo fueron vajillas y cerámicas, algunas de las más preciadas traídas desde Tzintzuntzan. AHeslp, Alcaldia Mayor, 1636.5 (caja 276), exp. 8, f. 1r. Agosto 8 de 1636. En cambio, los frutos de la región se empezaron a llevar a San Luis Potosí desde 1611, procedentes de la villa de Aguascalientes (Arnal, op. cit., p. 192). 
comercio que sin duda pretendió formalizarse con la creación de una alhóndiga.

La fundación en 1609 de una alhóndiga en el pueblo, ${ }^{16}$ permitió que el constante -aunque no siempre regulado- ingreso de arrieros y sabaneros con sus recuas cargadas de cereal y otras provisiones, tuviera un destino específico para la venta de los productos que traían. Al igual que en otras poblaciones, las leyes que regulaban la venta de los productos, señalaban que éstos no podían salir a la venta sin haber pasado tres días en exhibición en la alhóndiga; ${ }^{17}$ si el dueño de la mercancía o el arriero contaban con un encomendero, se podía evitar la estancia, de otra forma, para poder expender sus mercancías, era menester quedarse en el pueblo al menos tres días. La lógica implicaría que el pueblo debía contar con establecimientos que proveyeran un lugar para que pernoctaran los introductores, resguardaran sus animales y obtuvieran alimento y agua tanto para ellos como para sus bestias. Necesidad que en parte obedecía al hecho de que la alhóndiga española y su símil virreinal, habían perdido el servicio de hospedería que se brindaba en su antecedente hispanomusulmán. ${ }^{18}$

La alhóndiga hispanomusulmana había heredado de su antecedente oriental la función mercantil y de depósito, pero también la de

${ }^{16}$ AHESLP, Alcaldía Mayor, 1721 (caja 522), exp. 17, f. 1v. Septiembre 3 de 1721.

${ }^{17}$ AHESLP, Alcaldia Mayor, 1620.8 (caja 191), exp. 30, ff. 1r-3v. Diciembre 19 de 1620.

${ }^{18}$ Dentro de los conceptos hispanomusulmanes que fueron heredados al Nuevo Mundo, está la alhóndiga, cuya palabra proviene del árabe clásico funduq, el cual derivó en la palabra árabe-hispánica alfúndaq; en ambos casos servía para designar aquellos almacenes donde los comerciantes foráneos podían depositar los productos que llevaban a las villas, pueblos o ciudades (para su posterior repartimiento en los zocos-mercadosdonde eran comercializados al detalle), y que servían además para brindarles hospedaje. La tipología arquitectónica de los alfúndaq, constaba de un patio central rodeado de galerías sobre pilares; en la planta baja se situaban los almacenes y cuadras, mientras que en la alta se encontraba el espacio de alojamiento. Esta tipología que se repetía desde Persia hasta Espańa, tenía su antecedente en los caravansares, que no eran otra cosa sino los edificios diseñados especialmente para los mercaderes y sus mercancías a lo largo de las rutas de las caravanas, cuya finalidad era proveer un espacio de alojamiento y facilitar al mismo tiempo el comercio a través del mundo musulmán. Josefa Carmona Rodríguez, La alhóndiga malagueña: arquitectura y urbanismo, Diputación Provincial de Málaga, Biblioteca Popular Malagueña, 77, Málaga, 1997, 21. 
espacio de hospedería; sin embargo, esta versión habría de modificarse con el transcurso de los años, al ser retomadas por los cristianos las ciudades bajo dominio moro. La transformación fundamental que recibieron las alhóndigas fue la de restringir su función a la de ser meramente espacio de almacén y venta de productos foráneos, suprimiendo por completo su función de albergue ${ }^{19}$ lo que hubo de llevar a la creación de edificios que cubrieran la necesidad dejada de lado por las alhóndigas, apareciendo en consecuencia los mesones, posadas y figone ${ }^{20}$ para estos comerciantes. Sabemos que esta tipología -la de los mesones- se vinculó directamente a la alhóndiga y que incluso fueron los propios Reyes Católicos quienes establecieron en parte tal vínculo, como lo demuestra una orden emitida por tales al Concejo de Sevilla el 15 de marzo de 1491, en la cual planteaban la necesidad de que se construyera una alhóndiga y mesón de los moros, donde se les facilitara camas, ropas y cosas necesarias al precio acostumbrado, con lo cual evitarían que musulmanes y cristianos convivieran en el mismo mesón. ${ }^{21}$

De esta forma lo que habría de llegar al Nuevo Mundo serían estas dos tipologías por separado. En el caso de la ciudad de México, aunque ya había existido un intento de fundar una alhóndiga en $1538,{ }^{22}$ ésta se estableció formalmente hasta $1578 ;{ }^{23}$ en tanto que se tiene noticia de un primer mesón en dicha ciudad desde 1525, a cuyo cargo estaba Pedro Hernández Paniagua, quien había recibido permiso del Cabildo de la ciudad el $1^{\circ}$ de diciembre de ese año. ${ }^{24}$

${ }^{19}$ Ibidem, p. 26.

${ }^{20} \mathrm{Ibidem}$, p. 72. La diferencia, entre un mesón y una posada, sería que en el primero se daba alojamiento y comida, además de contar con un espacio suficiente para las bestias; la posada, en cambio, sólo brindaría hospedaje y sería menor en escala respecto de la primera. De acuerdo a la Real Academia Española, el figón es "una casa de poca categoría, donde se guisan y venden cosas de comer".

${ }^{21}$ La disposición real derivó en que el escribano hispalense, Nicolás Cabero, abriera la alhóndiga y mesón de Cabero "para moros y moras sean o no mudéjares". Celestino López Martínez, Mudéjares y moriscos sevillanos, Sevilla, Ed. Renacimiento, 1994, 19-20.

${ }^{22}$ Luis Chávez Orozco, Alhóndigas y pósitos, México, ANDSA, 1966, 24.

${ }^{23}$ Enrique Florescano, op. cit., p. 615.

${ }^{24}$ José Luis Martínez, Pasajeros de Indias. Viajes trasatlánticos en el siglo XVI, 2a reimpresión, México, Alianza (Universidad), 1997, 25-26. 
Sin embargo, de la existencia de estos dos factores (minería y comercio - alhóndiga) y del hecho de que cualquier población, como punto de estancia o de paso hacia algún lugar, debía contar con un mesón para los visitantes o transeúntes, ${ }^{25}$ no tenemos noticia de que hubiera mesón alguno -en el sentido formal de la palabra- en los primeros años de fundación de San Luis Potosí; tampoco durante todo el siglo xVII y la primera mitad del XVIII. No podemos decir tajantemente que no existieron porque de alguna forma sería una inconsistencia digna de profundizar, sino que simplemente no han llegado a nuestros días noticias de alguno en los periodos referidos, al menos durante los siglos XVI y XVII, donde por la distancia histórica se puede justificar que el registro de tales establecimientos se haya perdido.

Ahora bien, esta falta de noticias acerca de la existencia de mesones en San Luis Potosí a partir de su fundación y durante el siglo XVII no es privativa de la localidad, de hecho pocos son los trabajos que dan cuenta de esta tipología arquitectónica de servicio en el resto de la Nueva Espańa y, cuando lo hacen, descubrimos que en la mayoría de las fundaciones la escasez, o incluso la ausencia de éstos, es notoria. Si bien en la ciudad de México los había desde 1525, lo mismo que en el camino entre Veracruz y la capital de Nueva España, ${ }^{26}$ en otras fundaciones de importancia eran escasos. Tal es el caso de Guadalajara, ciudad que hacia 1565 apenas contaba con un par de posadas, lo que llevó al Cabildo a reprocharle a la Audiencia el no haber dotado a la ciudad de los servicios de hospedería necesarios. ${ }^{27}$ Algunos años después se fundó un mesón en la ciudad, pero éste cerró sus puertas hacia 1611 debido a que la clientela buscaba un lugar que contara, con lo que pudiéramos llamar, "mayores liber-

${ }^{25}$ Por ejemplo, para las rutas que conectaban el Bajío o Michoacán con las minas de Zacatecas, el virrey había otorgado concesiones para el establecimiento de ventas y mesones a lo largo de los caminos. Arnal, op. cit., p. 178.

${ }^{26}$ Guillermina del Valle Pavón, "La economía novohispana y los caminos de la Veracruz y Orizaba en el siglo xvı”, en Chantal Cramaussel, ed., Rutas de la Nueva España, El Colegio de Michoacán, México, 2006, 40. La autora menciona la existencia de mesones en Tlaxcala, Calpulalpan y Texcoco a partir de 1526.

${ }^{27}$ Thomas Calvo, op. cit., pp. 60-61. Las posadas eran las de Mateo de Villanueva y otra llamada "el convento" porque en ella estaban instalados los frailes agustinos 
tades". Al finalizar este siglo, se tiene noticia de al menos un mesón en Guadalajara y un copioso número de sitios que a la par del hospedaje ofrecían "otro tipo" de servicios. ${ }^{28}$

Si una ciudad tan importante como lo era Guadalajara no contaba con suficientes mesones, el panorama del norte de la Nueva Espańa, la Nueva Galicia y la Nueva Vizcaya, era menos halagüeño y sí contradictorio. Pareciera que, mientras la zona que comprendía de México hasta llegar a Zacatecas, sobre el Camino Real de Tierra Adentro, había sido dotada de mesones, ${ }^{29}$ ventas y postas, en el resto de la región, hacia el norte, era notoria su ausencia. Tepic, por ejemplo, a pesar de ser un centro estratégico regional, seguía sin un mesón al finalizar el siglo xviII, ${ }^{30}$ lo mismo que Parral, que a pesar de ser el centro comercial más importante de la Nueva Vizcaya ${ }^{31}$ no contaba con mesón alguno en el siglo XvII; ${ }^{32}$ lo mismo que Chihuahua, la que, a decir de testigos presenciales, todavía a principios del siglo XIX sus caminos estaban desprovistos de mesones, ventas y hospederías. ${ }^{33}$ En cambio, sabemos que en el siglo Xvi, fundaciones cercanas a lo que a la postre sería San Luis Potosí, prestaban el servicio de hospedería, como lo fue el caso de San Miguel y sus inmediaciones, donde, desde 1550 se contaba con un mesón que se le había concedido a Cristóbal de Ońate. ${ }^{34}$ Lo mismo sucedía con San Felipe, población que por ser el cruce de caminos entre Querétaro, San

${ }^{28}$ Ibidem, pp. 61-62. Al igual que en San Luis Potosí, es hasta principios del siglo xx que se tiene noticia de al menos una treintena de mesones en la ciudad.

${ }^{29} \mathrm{Y}$ aunque Zacatecas contó con mesones hasta ya muy tarde en el siglo XvIII (Infra), Fresnillo y Sombrerete los tuvieron desde muy temprano.

${ }^{30}$ Thomas Calvo, op. cit., p. 60.

${ }^{31}$ Chantal Cramaussel, Poblar la frontera..., p. 338. Población que además tenía un importante intercambio comercial con San Luis Potosí (véase p. 342, nota 271).

${ }^{32} \mathrm{Ibidem}$, p. 119. Lo que existía a mediados del siglo xvII, eran un hospicio y una posada manejadas por los frailes franciscanos (p. 118 y notas 168-69).

${ }^{33}$ Chantal Cramaussel, "El camino real de tierra adentro. De México a Santa Fe", en Chantal Cramaussel, ed., Rutas de la Nueva España, El Colegio de Michoacán, México, 2006, 321. Esto en parte se solucionó -al menos durante el virreinato- por medio de las haciendas, las cuales contaban con habitaciones para dar hospedaje a los viajeros (Idem, también nota 104), lo cual, como hemos establecido, creemos también pasó en San Luis Potosí.

${ }^{34}$ Aurelio de los Reyes, Los caminos de la plata, México, Gobierno del Estado de Zacatecas, Patronato de Minería Cinco Siglos en México, UIA, 1991, 60. También, Luis Arnal, op. cit., p. 184. 
Luis Potosí y Zacatecas, contó desde 1571 con varios mesones para brindar hospedaje a los arrieros y carreteros, y resguardar sus animales y carretas; ${ }^{35}$ lo mismo que las poblaciones que en su momento pertenecieron a la alcaldía de Guanajuato, como lo fue Comanjá, poblado que desde finales del siglo Xvi contó con un mesón. ${ }^{36}$

¿Qué es lo que origina que no tengamos noticia ni se haga mención de mesón alguno a partir de la fundación de San Luis Potosí y a lo largo del siglo Xvir? Acaso en la etapa párvula del pueblo lo que existieron fueron "ventas" a lo largo de los caminos que lo conectaban con los puntos inmediatos, y cuya ubicación original obedecía a la necesidad de concentrar y organizar el aprovisionamiento de los viajeros. En este tipo de establecimientos se ofrecía el servicio de alojamiento y expendio de bastimentos, además de haber estado muy ligados a los primeros ańos del virreinato y en cada uno de los procesos de fundación de pueblos villas y ciudades, ${ }^{37}$ a grado tal que incluso quedó plasmada en las Leyes de los Reinos de Indias, tanto la necesidad de que existieran donde no los hubiere, como de que se ofreciera el servicio por un justo precio. ${ }^{38}$ Por otro lado, el que San

${ }^{35}$ Luis Arnal, op. cit., p. 272. El autor menciona que todavía a mediados del siglo XIX existían en San Felipe cinco mesones con todos los servicios (p. 268), lo que también sirve para ilustrar la evolución entre un poblado como éste y San Luis Potosí, donde a mediados del mismo siglo se contaba ya con una veintena de estos establecimientos.

${ }^{36}$ Archivo General de la Nación (AGN), Real Audiencia, Indios, vol. 5, exp. 14, f. 73v. 1590. En este documento se le informó al alcalde mayor de Guanajuato que habiendo hecho los naturales de Zipiajo un mesón para hospedar viajeros, no les fuera permitido ir a prestar sus servicios al mesón de Comanjá.

${ }^{37}$ Tenemos noticia de que ya en 1525 se habían instalado ventas a lo largo del camino entre Veracruz y México, uno de los primeros dueños fue Francisco de Aguilar, quien las tenía en la Villa Rica de la Veracruz y otra más entre Medellín y Veracruz (José Luis Martínez, op. cit., p. 25). En la década de 1530 se abrió entre Veracruz y la ciudad de México un camino que se conocería como de "las Ventas", precisamente por la existencia de éstas (Del Valle Pavón, op. cit., p. 45), y lo mismo sucedió en el camino llamado "de los Ángeles" -entre México y Puebla-, que contó desde muy temprano con ventas instaladas a lo largo de su trayecto (Ibidem, p. 46. En las páginas 59 y 60, la autora da una lista detallada de los caminos y ventas entre Veracruz y Orizaba). De alguna forma estos establecimientos emulaban a los caravansares que hemos descrito.

${ }^{38}$ Recopilación de Leyes de los reinos de las Indias, 1681, Edición facsimilar Conmemorativa al V Centenario del Descubrimiento de América en el LXXV Aniversario de la Escuela Libre de Derecho, 5 tomos, Miguel Ángel Porrúa y Escuela Libre de Derecho, México, 1987, tomo II, libro v, título II, "De los gobernadores y regidores", p. 148v, ley 
Luis Potosí no hubiera nacido como un presidio, sino como un real minero, pudo haber influido para que no hubiese una vocación de asilo y hospedaje desde su nacimiento; recordemos tan sólo como muchos de los presidios eran al mismo tiempo postas y mesones -o terminaron por serlo-, o viceversa, comenzando por ser posadas que concentraban las caravanas de viajeros para formar convoyes o abastecerlos, terminaron por fortificarse, dando pie a la formación de presidios; ${ }^{39}$ obviando, por supuesto, la posterior evolución en villas y pueblos que algunos de estos presidios presentaron.

Si bien no contamos con referencias de mesones o ventas, de lo que sí tenemos noticia es de la existencia de al menos un par de casas de hospedería ${ }^{40}$ en la ciudad. La más importante era la llamada de "San Francisco" (a las espaldas del convento del mismo nombre) porque era manejada por religiosos franciscanos desde finales del siglo XVII y principios del XvIII. Este tipo de estancias tenían una función hospitalaria se brindaba alojamiento a los viajeros. Estas casas de hospedería generalmente eran administradas por órdenes como los juaninos, hipólitos y betlemitas, ${ }^{41}$ lo cual podía garantizar cierta seguridad; no obstante, la conformación arquitectónica de tales establecimientos no cubría en su totalidad las necesidades especializadas que otro tipo de viandantes tenían, como lo eran grandes corrales para sus animales y espacios para carretas; sin mencionar la "libertad" ${ }^{2}$ que un mesón significaba respecto a la estricta obser-

XviII. En esta ley se establecía que los gobernadores, regidores y alcaldes no sólo visitaran los mesones, ventas y tambos que hubiere en los pueblos y caminos, sino que ordenaran que los hubiera donde fuera necesario o, por lo menos, que hubieran casas de acogimiento para los caminantes. Por su parte, en el libro IV, título XVII, "De los caminos públicos", p. 112, la ley primera establecía la conveniencia de que "en los mesones, posadas y ventas, se den a los caminantes bastimentos y recaudos necesarios, pagándolo por su justo precio".

${ }^{39}$ Luis Arnal, op. cit., pp. 45 y 183. Algunos presidios fueron al mismo tiempo mesones, trojes y lugares de defensa; en el caso de la jurisdicción de San Luis Potosí, se tiene la referencia de Bocas de Maticoya.

${ }^{40}$ Cubriéndose con ésta en parte lo dispuesto en las Leyes de los Reinos de Indias, relativas a que al menos hubiera casa de acogimiento. Supra.

${ }^{41}$ Carmen Venegas Ramírez, Régimen hospitalario para indios en la Nueva España, INAH, SEP, México, 1973, 7.

${ }^{42}$ Sobre todo si consideramos que en los mesones, además de cuartos y corrales, se podía disponer de tienda y, en algunas ocasiones, obtener diversión por medio de la 
vancia que podía suponerse en una hospedería manejada por religiosos.

Los franciscanos no sólo se encargaron de brindar este servicio en San Luis Potosí, sino que extendieron esta práctica en los territorios circunvecinos, como lo demuestra el hospedaje que recibió el alcalde mayor don Martín de Mendalde en la estancia de San Francisco, camino a San Luis Potosí, durante su visita a la frontera de Guadalcázar en $1675 .{ }^{43}$

En 1733, el hospicio primitivo que tenían los franciscanos en la ciudad fue comprado por fray Nicolás de Jesús María de la orden del Carmen, para que funcionara como hospicio carmelitano, ${ }^{44}$ es decir, una casa privada para que vivieran en ella los carmelos sin tener una relación directa y formal con el exterior.

La otra hospedería de la cual tenemos noticia, data también del siglo Xvir y se encontraba ubicada en el santuario y ermita de Nuestra Señora de Guadalupe. Este pequeño espacio había sido mandado edificar en 1656 por el fundador de la ermita (el tesorero real Francisco de Castro y Mampaso), para aquellas personas -así de la ciudad como de otras jurisdicciones- que iban a velar la virgen. ${ }^{45} \mathrm{Si}$ bien esta hospedería se suma a la historia de los espacios de alojamiento, su finalidad era muy específica y, por tanto, limitante.

Si la falta de mesones a lo largo del siglo Xvir es patente, resulta más notoria aún su ausencia en la mayor parte del siglo XVIII, sobre todo si consideramos que las rutas se habían consolidado y que era común el tránsito, así de pasajeros, como de arrieros y carreteros que

existencia de alguna taberna donde beber y jugar (la cual podía estar incluida en la misma tienda). Por otro lado, esta realidad hacía que tanto en Espańa como en la Nueva Espańa, se tuviera que poner mucha atención a los inquilinos de los mesones, ya que en ellos se podían gestar focos de delincuencia (Ricardo Izquierdo Benito, "Toledo en 1492", en Pedro Miguel Ibánez, coord., Memoria del Nuevo Mundo. Castilla-La Mancha y América en el quinto centenario, Universidad de Castilla-La Mancha, España, 1992, 65). Realidad que condujo a que existiera la preocupación -como se verá- de tener conocimiento de quiénes se hospedaban tanto en casas particulares como en mesones.

${ }^{43}$ AHESLP, Alcaldía Mayor, 1676.2 (caja 420), exp. 7. Julio 27 de 1675.

${ }_{44}^{4}$ Alfonso Martínez Rosales, El gran teatro de un pequeño mundo. El Carmen de San Luis Potosí, 1732-1859, El Colegio de México, Universidad Autónoma de San Luis Potosí, México, 1985, 137.

${ }^{45}$ AHESLP, Ayuntamiento, 1685-1694, f. 219r. Julio 19 de 1691. 
llevaban mercancías a muy diversas latitudes. San Luis Potosí se había convertido en un paso obligado hacia el norte, así como punto de venta y abasto al que llegaban artículos de lo más variado. ${ }^{46} \mathrm{La}$ extrañeza se incrementa si se considera además que, desde las postrimerías del siglo XVII, la zona de suministro agrícola de San Luis Potosí -principalmente de cereales- había crecido considerablemente, por lo que ya no podríamos hablar de un Hinterland, sino de unos Hinterländer ${ }^{47}$ que cubrían, desde diversas regiones (figura 2), la necesidad de maíz y harina (además de otros productos) que tenía la ciudad.

Por otro lado, la privilegiada ubicación geográfica de San Luis Potosí tampoco era una novedad, a grado tal que era descrita como "la garganta por donde han de transitar todos lo más lugares de la tierra adentro", llegando incluso a ser considerada "la capital de aquellas distantes poblaciones" ${ }^{48}$ en referencia a los puntos septentrionales que a través de ésta se llegaban. Siendo entonces la ciudad un paso regular de viajeros, carreteros, arrieros, mineros y soldados, cabe preguntarse porqué la falta de noticias acerca de mesones en San Luis Potosí en la mayor parte del siglo XviII.

${ }^{46} \mathrm{El}$ recuento de una ruta hecha en 1755 , por un arriero de nombre José Ladrón de Guevara en un lapso de tres meses, nos permite tener una idea de las distancias y puntos que tocaban los arrieros: "Salió la recua de don José Ladrón de Guevara de San Luis Potosí a Chihuahua, con 26 mulas con géneros de tienda...”, de aquella regresaron vacíos hasta San Luis Potosí, desde donde hicieron dos viajes a Guadalcázar con azogue, regresando del primer viaje cargados de metal a San Luis Potosí, y del segundo vacíos. Luego llevaron de La Parada de Luna, fardería de nuevo a Guadalcázar, de donde trajeron azúcar para San Luis Potosí. De ahí se fueron a la "Deseadilla" donde cargaron lana para México, de donde partieron vacíos a Puebla a cargar harina para Veracruz, de la cual volvieron cargados de fierro para México. De México se fueron a San Felipe Iztacuistla a agostar las mulas. Luego regresaron a Puebla vacíos para cargar harina que llevarían a la villa de Córdova, y de ésta se fueron vacíos a Orizaba, de la cual volvieron cargados de papel para Puebla. De esta última pasaron cargados de harina para Córdova, y de allí se fueron vacíos a Orizaba, de donde regresaron cargados de cacao para Puebla, de la cual llevaron de nuevo harina a Córdova. Partieron vacíos para Orizaba, de donde trajeron algodón a San Felipe, y habiéndose vuelto a Orizaba por algodón, salieron con rumbo a Cosamaloapan. AHESLP, Alcaldía Mayor, 1755.3 (caja 590), exp. 13, ff. 8v-9r. Septiembre 6 de 1755.

${ }^{47}$ Palabra que es el plural en alemán para el concepto Hinterland.

${ }^{48}$ AHESLP, Ayuntamiento, 1763-1769, exp. 4, f. 173v. Octubre 12 de 1770 . Esto a decir del alcalde mayor, don Andrés de Urbina y Eguiluz. Con el apelativo de "la garganta de la tierra adentro" se le conocía a la región comprendida entre Querétaro, San Felipe, San Luis Potosí y San Miguel. 
Figura 2. Mapa de zona de abasto para San Luis Potosí, segunda mitad del siglo XVII

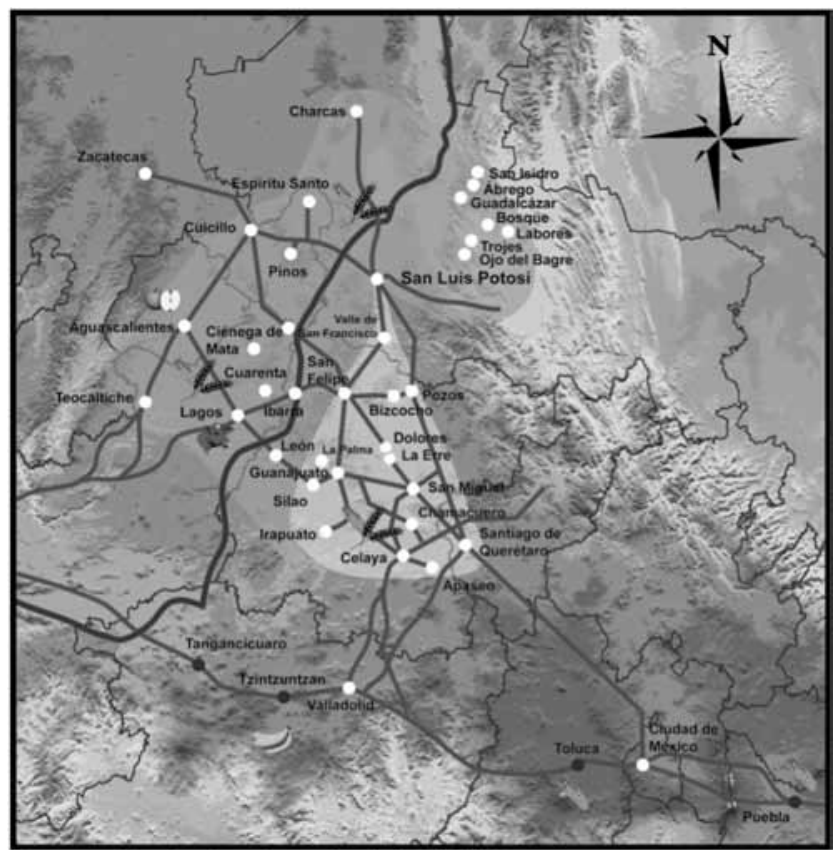

Puntos geograficos basados en las coordenadas de INEGI (IRIS).

Mapa: Armando Hernàndez Soubervielle / Ing. Carlos A. Nüñez Ortiz.

Crecimiento de la zona de abasto
de cereales segunda mitad del sigio XVII Abasto de frutos de tierra caliente
Zona de abasto de cereales existente
desde la primera mitad del siglo XVII

La respuesta puede ser más simple de lo que se piensa: las largas estancias de los arrieros y carreteros - tan sólo por pensar en una mínima parte de la posible clientela de un mesón- en la ciudad, a la espera de poder vender el maíz u otras mercaderías (cuando no echaban mano de un encomendero), aunado a lo caro que podía resultar el rentar cuartos por varios días, los obligaba a buscar otras opciones, disminuyendo así la demanda de un mesón y por consiguiente propiciando su inexistencia. 
Si las jornadas eran cortas, los arrieros podían dejar sus bestias en el corral que la alhóndiga tenía, ${ }^{49}$ en tanto que ellos, en algunas ocasiones, podían quedarse en los cuartos que rentaban dentro del edificio para expender su maíz, ${ }^{50}$ de forma tal que incluso el mayordomo de las fincas de la ciudad estaba al pendiente -al mismo tiempo que el arrendatario o alcaide de la alhóndiga- de que los cuartos de la alhóndiga estuvieran en óptimas condiciones para que los forasteros que iban a aquella a vender su maíz no tuvieran motivo para "irse a vivir a otras partes diciendo que no están seguros y que los pueden robar" ${ }^{51}$ Si esto no era posible por encontrarse llena la alhóndiga, lo común era que llegaran y rentaran casas en los barrios extramuros de la ciudad. La operación consistía en que los arrieros o forasteros se presentaban en casas que se sabía podían rentar (en algunas ocasiones éstas eran casas de capellanías que estaban sujetas a renta), solicitándole al dueńo que les arrendara el espacio por determinado número de días, durante los cuales los propietarios o se mudaban con familiares o se quedaban en la misma vivienda. En el caso de los introductores de bastimentos y granos, éstos buscaban aquellas casas que contaran con un corral que les permitiera resguardar sus animales. El problema radicaba en que siendo extraños, podían fácilmente abusar de la confianza de los arrendadores. ${ }^{52}$ Esta

${ }^{49}$ Tenemos noticia de estos corrales desde muy temprano en la conformación de la alhóndiga. AHESLP, Alcaldía Mayor, 1629.1 (caja 232), exp. 13, f. 1r. Enero 29 de 1629.

${ }^{50}$ Esto por otro lado siempre fue ocasión de quejas ya que comúnmente los arrieros empleaban en la noche las bodegas rentadas en la alhóndiga para jugar y meter mujeres (AHESlP, Alcaldía Mayor, 1693.1 (caja 462), exp. 6, f. 12v-14v. Febrero 21 de 1693), lo cual al parecer era cosa común en las alhóndigas, como la de México, en la que desde 1619 se habían prohibido los juegos de cualquier índole, así como la presencia de mujeres de dudosa reputación (Chester L. Guthrie, "Trade, Industry, and Labor in Seventeenth Century Mexico City", en Revista de Historia de América, núm. 7, diciembre de 1939, Instituto Panamericano de Geografía e Historia (OEA), 1939, 110).

${ }^{51}$ AHESLP, Ayuntamiento, 1749-1795, exp. 2, f. 3r. Diciembre 24 de 1749.

52 De hecho, siendo pueblos de indios los ubicados extramuros de la ciudad y no existiendo en ellos mesón o tambo, se estaba violando una disposición contenida en las Leyes de los Reinos de Indias, la cual indicaba que los gobernadores deberían proveer que los hubiera en los pueblos de indios y que, además, donde hubiere éstos, no se fuera a posar a la casa de los indios con la finalidad de evitar todo abuso (Recopilación de Leyes de los reinos de las Indias, op. cit., tomo II, libro IV, título XVII, "De los caminos públicos", p. $114 \mathrm{v}$ ), tal y como estaba sucediendo en la práctica en San Luis Potosí. Este mismo pro- 
costumbre que se venía practicando por mucho tiempo llevó a que el 20 de enero de 1750, el alcalde mayor don Luis Lasso de la Vega Ponce de León expidiera un bando en el que prohibía que se hospedaran forasteros en casas particulares por las muchas muertes, robos y demás que se habían experimentado. Ordenaba además que cada habitante diera aviso de la llegada de forasteros cuya persona, procedencia o vecindad no se pudiera verificar. La disposición se hizo llegar a cada uno de los siete pueblos de indios, ya que era allí donde se hospedaba de común el grueso de estos visitantes. ${ }^{53}$

La otra opción era que los viajeros pernoctaran en parajes ${ }^{54}$ públicos y conocidos. Ésta era una costumbre a lo largo de los caminos virreinales, y la fama de cada uno de éstos les venía por lo seguro y cómodo que resultaban o por los hurtos y ataques a los que se exponían los viajeros. ${ }^{55}$ En el caso de San Luis Potosí se contaban con varios parajes antes de entrar a la población; baste mencionar el llamado paraje del Salitral que desde el siglo xvi funcionaba como punto de descanso entre Zacatecas y San Luis Potosí, camino a Charcas. ${ }^{56}$ En lo que era propiamente la ciudad de San Luis Potosí, uno de los parajes más usados era el que se encontraba atrás del convento del Carmen, cuya mala fama la había ganado a fuerza de ser frecuentes los robos a los viandantes. En 1764, por ejemplo, Juan Francisco Sánchez, compareció ante la justicia local informando que el día 9 de noviembre había llegado a la ciudad "a deshoras [y]

blema se presentó, por ejemplo, en Guadalajara, donde por falta de instalaciones de hospedería, los indios de los pueblos vecinos sufrían múltiples abusos (véase Thomas Calvo, op. cit., p. 61).

${ }^{53}$ AHESLP, Alcaldía Mayor, 1750.1 (caja 576), exp. 23, f. 1r. Enero 20 de 1750.

${ }^{54}$ La idea básica del paraje era la de una extensión o planicie donde se podía reposar algunas horas para tomar un respiro y continuar el viaje. Roberto Carrillo Acosta, El papel de los mesones en Zacatecas. El mesón de Tacuba durante los siglos XVIII y XIX, tesis de grado de Maestría en Historia, Zacatecas, UAZ, 2008, 14.

${ }^{55}$ Por ejemplo, cercano a Jalapa, antes de tomar el camino real entre Puebla y México, se encontraba el paraje denominado La Rinconada, famoso como zona de descanso y por las aguas medicinales que se podían tomar. María Justina Sarabia Viejo, "Los caminos del Golfo de México", en Chantal Cramaussel, ed., Rutas de la Nueva España, México, El Colegio de Michoacán, 2006, 104.

${ }^{56}$ Luis Pedro Gutiérrez Cantú, La provincia de los llanos. Charcas 1550 a 1610, Copocyt, Conaculta, Patronato para el fomento cultural de Charcas, México, 2005, 71. 
por no haber en ella casa de mesón, paré en un mezquite tras el convento de nuestra señora del Carmel [sic], lugar conocido por paraje público", donde había coincidido con otros viajeros que pernoctaban en el mismo sitio. El problema devino una vez dormidos él y su mozo, ya que fueron "atacados, heridos y robados". ${ }^{57}$ Hechas las pesquisas se dio con los ladrones, quienes resultaron vivir frente al citado paraje, y aunque en las declaraciones éstos afirmaron que, "tras oír el alboroto del robo", habían ayudado al herido cubriéndolo "caritativamente con unas mantas", ${ }^{58}$ terminaron presos en la cárcel de la ciudad.

Finalmente estaban los viajeros pertenecientes a un estrato más pudiente, quienes no ocupaban de un mesón, ya que bien podían encontrar alojamiento en las casas de particulares (ya fuesen de parientes, amigos, socios comerciales o recomendados) o, de acuerdo a las circunstancias de la visita, podían solicitar asilo en los conventos.

Por otro lado, a la posible falta de demanda que resultaba de las opciones de hospedaje arriba descritas, se le sumaba el factor inversión. Establecer un mesón implicaba cubrir ciertos requisitos. Primero el interesado debía contar con un predio y una construcción tal que pudiera ser sujeta de considerarse mesón, requisito en el que se iba una inversión muy importante. Una vez contando con la infraestructura, se procedía a la presentación de una solicitud a las autoridades - quienes a su vez imponían un arancel, además de establecer las normas que debía cubrir el solicitante ${ }^{59}-$, lo que implicaba una nueva inversión además de la consecuente tramitología administrativa. Con esto en mente, podemos suponer que casi cualquiera con un mínimo de inversión podía establecer una "venta", no así un mesón, cuyas características (de servicio ofrecido, espacio utilizable y construido) implicaban una fuerte inversión monetaria.

Es hasta 1775 que tenemos noticias concretas acerca de la existencia de un mesón en San Luis Potosí, ${ }^{60}$ el cual estaba arrendado

\footnotetext{
${ }^{57}$ AHESLP, Alcaldía Mayor, 1764.1 (caja 608), exp. 1, f. 1r. Enero 10 de 1764.

${ }^{58}$ Ibidem, ff. 2r-3r. Enero 16 de 1764.

${ }^{59}$ Carrillo Acosta, op. cit., p. 14.

${ }^{60}$ Aunque no tenemos noticias de su ubicación y características.
} 
por un valenciano de nombre Manuel Gitart. Sabemos de este mesón gracias a la queja que el propio Gitart le hizo llegar al alcalde mayor Antonio Joaquín de Villaurrutia respecto a que siendo el arrendatario "del único mesón que había en la ciudad", y ésta -la ciudad- "el paso regular y según dicen vulgarmente la 'garganta de la tierra adentro'”, sus ingresos se veían mermados considerablemente en función de que se hospedaban allí, sin pagar, los soldados de las tropas transeúntes con sus recuas y mozos; sucediendo lo mismo con los que traían "el encargo de la plata" (el convoy de plata), llegándose al punto de encontrarse todo (cuartos y caballerizas) completamente ocupados, sin que se pudiera hospedar pasajero alguno. ${ }^{61}$ La queja llegó hasta la Real Audiencia de México, por lo que se comisionó al auditor general Domingo Balcarte para que revisara el caso, tras lo cual se ordenó que se destinara el mesón al uso de pasajeros y viandantes, y que los soldados se hospedaran tanto en las Casas Reales desocupadas, como en lo que se pudiera aprovechar del cuartel o, en su defecto, en las casas de los vecinos que tuvieran deuda con la Corona; ${ }^{62}$ o bien, que los soldados, de su peculio, pagaran hospedaje en el mesón.

Enterado de la orden expedida desde México, el alcalde Villaurrutia comunicó los términos de la misma a los soldados Vicente Pedrete y Juan Lámbarri, quienes se encontraban hospedados en el mesón. Finalmente éstos decidieron quedarse junto con sus subalternos en el mesón, arrendándole los cuartos a Gitart. ${ }^{63}$ La queja deja entrever de forma tangencial una realidad que sufría la ciudad: no sólo se tenía la limitante de contar con un solo mesón, sino que además no había cuartel para hospedar a los soldados, sin mencionar ya que las Casas Reales, a pesar de estar desocupadas en la mayoría de sus cuartos, eran prácticamente inservibles para cualquier tipo de alojamiento.

${ }^{61}$ AHESLP, Alcaldía Mayor, 1775.2 (caja 633), exp. 22, f. 1rv. Julio 27 de 1775.

${ }^{62}$ Lo cual suponía otra modalidad para suplir la necesidad que tenía la ciudad de un mesón.

${ }^{63}$ AHESLP, Alcaldía Mayor, 1775.2 (caja 633), exp. 22, f. 1 rv. Julio 27 de 1775 . Nuevamente la "libertad" que suponía hospedarse en un mesón, al amparo de la privacidad, pudo ser factor determinante para que los soldados prefirieran pagar su estancia a mudarse a otro lado. 
Transcurrido un año después de la queja presentada por Gitart, el doctor Casimiro José Martínez - quien era dueño del mesón-, se quejó de aquél, porque desde el mes de agosto del año anterior (apenas un mes después de recibida la orden de la Real Audiencia de que los soldados pagaran hospedaje), Gitart había abandonado la ciudad sin dejar apoderado que representara a su persona, sino tan sólo a un mozo llamado Miguel de Aguilar como encargado del mesón, aunque sin dinero para satisfacer la renta del edificio, la cual se había fijado en 200 pesos anuales prorrateados en mensualidades. ${ }^{64} \mathrm{El}$ dueño solicitó se le devolviera el mesón para poder administrarlo, dando por cancelado el contrato que tenía con Gitart, cosa que finalmente se le concedió. La salida repentina del valenciano se presta a cualquier tipo de especulación; lo que no deja de ser una extraña coincidencia es que una vez que se le solucionó aquello de lo cual se quejaba, saliera con tanta inmediatez. El que Casimiro Martínez estuviera ahora al frente de la administración de su mesón, propició que éste se empezara a conocer como el "mesón de don Casimiro". ${ }^{65}$

En 1779, tenemos noticia de otro mesón, el cual había sido propiedad del escribano Ignacio Antonio de Fauduas, ${ }^{66}$ y gracias a una

${ }^{64}$ AHESLP, Alcaldía Mayor, 1776.1 (caja 635), exp. 14, ff. 1r-2r. Febrero 27 de 1776.

${ }^{65}$ AHESLP, Alcaldía Mayor, 1784.2 (caja 658), exp. 25, f. 1r Noviembre 4 de 1784. En este expediente se da cuenta de un problema entre don Casimiro Martínez y el prior del convento de San Juan de Dios, porque del hospital le habían prestado un colchón, una almohada y su funda al mesón, para que fueran utilizadas por un caballero que había estado de paso por la ciudad -con esto se hace más evidente el tipo de servicio y menaje con que contaba un mesón regular, siendo el colchón, almohada y funda, un lujo destinado en este caso para alguien en particular-. El mesonero no regresó el menaje prestado, lo que fue ocasión de un reclamo y fuerte discusión entre el prior, la mujer del médico y el médico mismo, quien terminó golpeando al padre juanino. El médico en su defensa argumentaba que los padres no eran, ni por mucho, personas pacíficas, para lo cual traía a memoria que éstos andaban armados de navaja y que ya había existido un incidente de un padre matando a otro dentro del convento juanino. En lo arquitectónico sabemos que el mesón contaba con "un patio muy grande" (f. 15v), gracias a la declaración de la esposa de don Casimiro, quien llamó al carpintero a gritos - el cual se encontraba del otro lado del patio- para que la auxiliara con el prior que la estaba insultando, pero que por ser el patio muy grande no había llegado a tiempo para escuchar todos los insultos espetados por el juanino, lo cual corroboró el propio carpintero.

${ }^{66}$ Fue el escribano Fauduas uno de los más importantes y más longevos con que contó la ciudad. Lo encontramos ya como escribano en San Luis Potosí a principios del siglo XviII hasta 1776, año en el que muy posiblemente murió (AHEsLP, Alcaldia Mayor, 1776.2 (caja 
deuda de 400 pesos que éste había contraído con la obra del Santuario y su consecuente falta de pago, fue que se levantó un inventario y avalúo de sus propiedades, entre las que se encontraban la hacienda de Corcovado y un mesón llamado "de Fauduas", para con ello cubrir el capital y los réditos que adeudaba. ${ }^{67}$ Es gracias a este avalúo que ha llegado a nuestros días la descripción y ubicación de este mesón. El encargado de hacer el inventario fue José Vitorio de los Candelarias, maestro de arquitecto, vecino del barrio de San Cristóbal del Montecillo, quien dio cuenta de un

Mesón cerca del convento de Nuestra Seńora de la Merced, linda por el norte con la tenería de don Manuel Bollolo, calle en medio, y por el sur con la corriente de los Tepetates, por el poniente con la calle que va a la Santísima Trinidad y por el oriente linda con la calle de la Cruz.

De frente 70 varas y 2 tercias y de fondo $61 \mathrm{y} 3 / 4$, a 3 reales vara, 45 pesos;

Zaguán, de cinco varas de ancho y 10 de fondo y $41 / 4$ de alto;

una sala, de 8 de largo y 5 de ancho y alto $41 / 2$;

una sala de la esquina, largo 6 ancho 5;

sala que cae al fondo, largo 8 ancho 5;

pieza del pozo con brocal;

sala, largo 8 ancho 5;

sala, largo 8 ancho 5;

pieza de recámara, largo $61 / 4$ ancho 5 ;

recámara, largo $52 / 3$ ancho 5 ;

cuarto, largo 5 ancho 5;

9 cuartos caen a la calle de don Manuel Bollolo y 6 caen al patio, viendo sus puertas al poniente;

10 arcos medio punto y medio sus paredes, cogen techo de 55 varas;

otros 7 , trecho de $372 / 3$ varas;

pieza de adoquín, largo 4 varas y ancho 3 y hondo una vara;

dos salvaderas redondas, de ancho de vara y $2 / 3$ y fondo de vara $y 3 / 4$;

tres hoyos de curtir cascalote;

636), exp. 11, f. 154r. Julio 19 de 1776). Por su avanzada edad, dejó de estampar su firma en varias diligencias y de pagar varias deudas, lo que fue ocasión de una investigación muy acuciosa que terminó en el embargo de muchos de sus bienes, como se verá.

${ }^{67}$ AHESLP, Alcaldia Mayor, 1779.3 (caja 643), exp. 3, ff. 1r-4r. Julio 7-21 de 1779. 
Figura 3. Reconstrucción hipotética de la planta y alzado del mesón de Fauduas. Plano: A. Hernández Soubervielle, Arq. Osvaldo E. Chávez Gómez

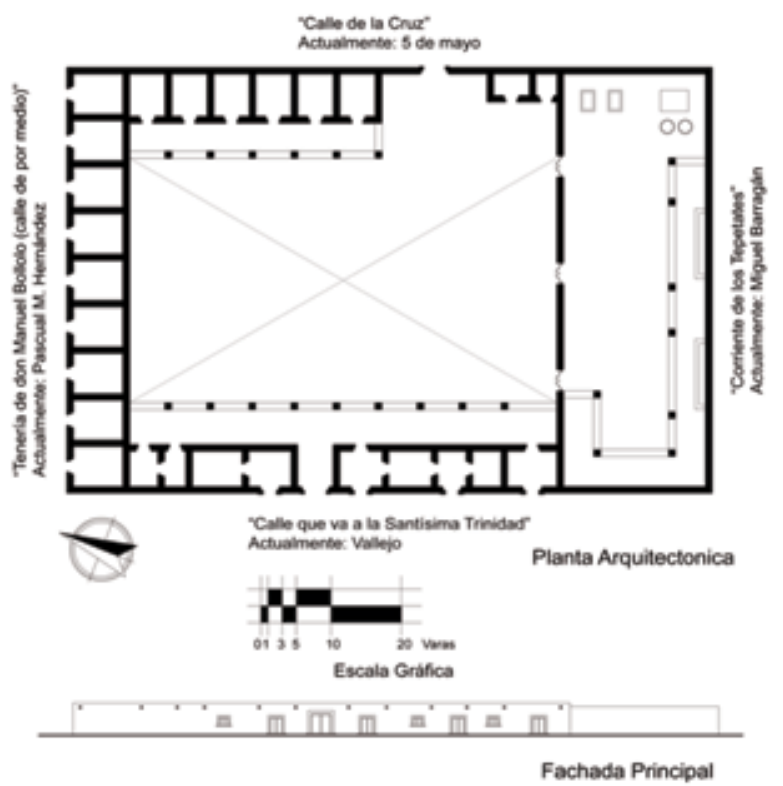

112 varas de pared de corral, largo 61 varas y ancho de $261 / 2$;

pozo en el corral;

tres piletas para lavar, de ancho una vara y dos sesmas y hondo lo mismo; pieza de la noria, con agua buena, embrocalada de calicanto, con dos piletas tarjas, largo $31 \frac{1}{2}$; noria, largo 3 ancho $1 \frac{1}{2}$;

todo lo cual suma 928 pesos 6 reales. ${ }^{68}$

El maestro arquitecto añadió que el mesón estaba muy deteriorado y que contaba con tienda en la esquina, ${ }^{69}$ datos con los cuales hemos realizado una reconstrucción hipotética (figuras 3 y 4 ), localizando además, con toda certeza, la ubicación del mesón en lo que

${ }^{68}$ Ibidem, f. 13-14. Abril 7 de 1780.

${ }^{69}$ Ibidem, f. 8. 
Figura 4. Reconstrucción hipotética del isométrico del mesón de Fauduas. Plano: A. Hernández Soubervielle, Arq. Osvaldo E. Chávez Gómez

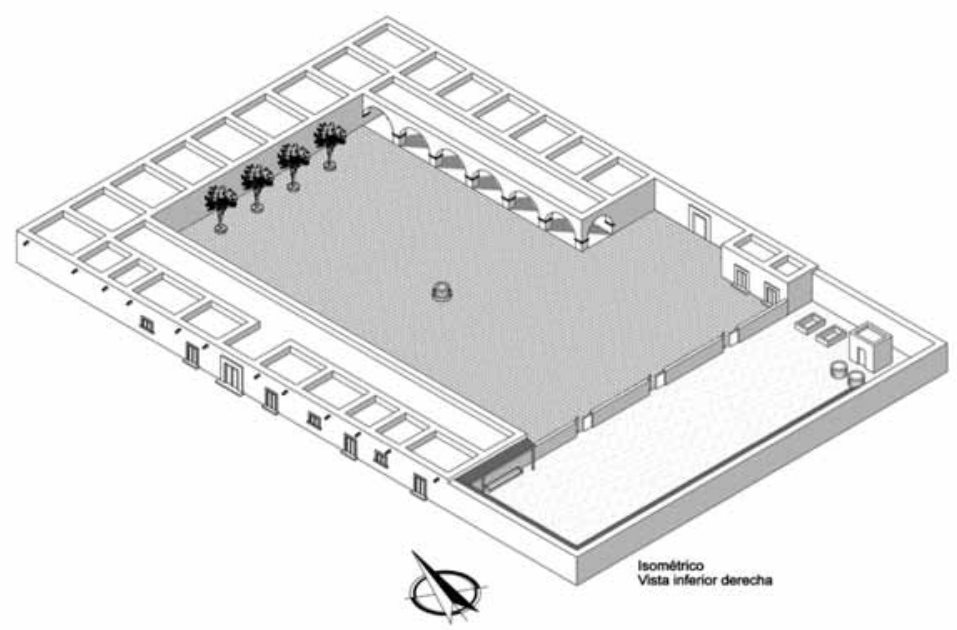

hoy son las calles de 5 de mayo en el costado oriente, Vallejo en el costado poniente, Miguel Barragán en el sur y Pascual M. Hernández en el norte; $y$ aunque las cuadras han variado considerablemente de la traza original novohispana, la ubicación de este edificio es muy precisa.

A diferencia del mesón de don Casimiro - del cual no contamos ni con su descripción ni con su ubicación, salvo la inferencia de que se encontraba dentro de la ciudad-, el de Fauduas, contaba con la gran ventaja de localizarse muy cerca de lo que era la garita de México, la cual se situaba a un costado del convento de la Merced, justo a la entrada de la ciudad proviniendo del camino real a México. Su ubicación se volvía así estratégica, ya que era precisamente de la ciudad de México y los puntos intermedios, de dónde se tenía mayor afluencia a la ciudad; baste recordar que el abasto de cereales provenía principalmente de Celaya, Irapuato, San Felipe, San Miguel y Silao, poblaciones que podían conectarse a través del Valle de San Francisco (hoy Villa de Reyes) con la ciudad de San Luis Potosí. 
Figura 5. Manuel Pascual Burgoa (Atrib.). Plano de la ciudad de San Luis Potosí dividida en cuarteles, 1794. Archivo General de Indias. M. y P. México y La Florida, 456. Las acotaciones son nuestras

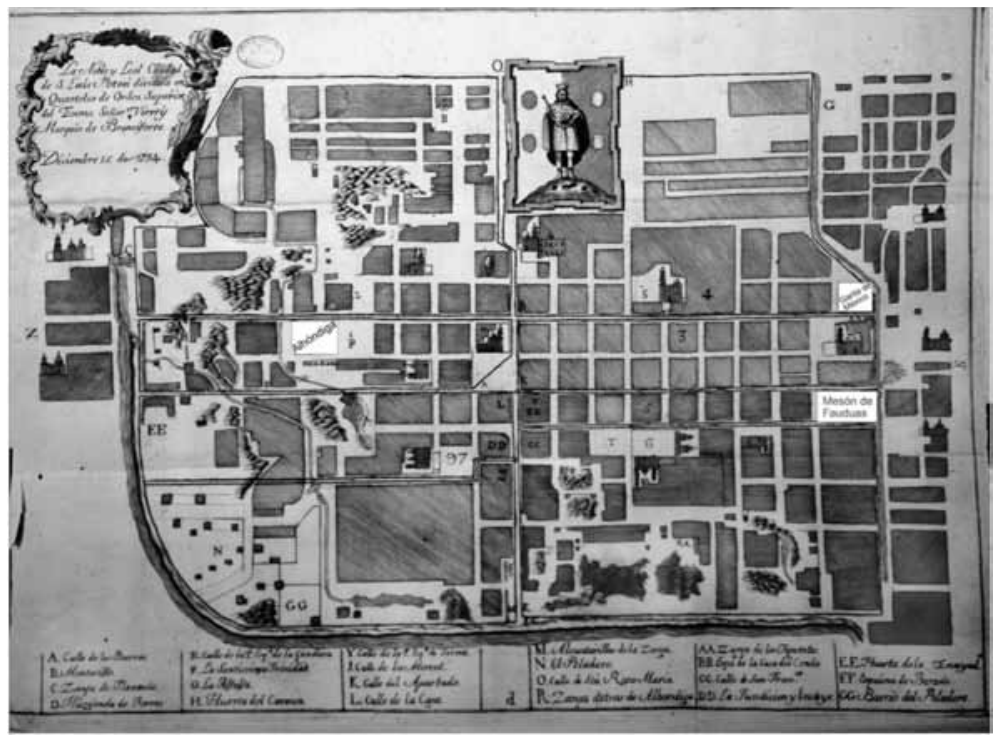

De esta forma, una vez descargadas las recuas en la recién construida alhóndiga ${ }^{70}$-a la cual se llegaba en derechura desde la garita de México (figura 5)-, los arrieros podían regresar con toda comodidad a guardar y reposar sus animales en el mesón de Fauduas (el que, como ya hemos visto, contaba con un magnífico corral), preocupándose tan sólo de sus posturas y ventas en la ciudad. La ubicación de este mesón ofrecía una logística y comodidad inmediatas, pareciendo estar diseñado ex profeso (por sus características arquitectónicas y espaciales) para los arrieros y carreteros que entraban por el sur a la ciudad.

Haciendo un cálculo aproximado y considerando que en el plano hipotético que hemos diseñado de acuerdo a los datos proporcionados por el maestro arquitecto, establecimos cuartos para

${ }^{70}$ Obra que se había concluido en 1777. 
hospedaje de 4.75 de ancho x 5.90 metros de fondo para los exteriores y 4.20 por 5.00 metros para los interiores, el mesón de Fauduas podía albergar con desahogo a doce personas acostadas en cada uno de los cuartos exteriores y diez en los interiores. Este cálculo considera, por supuesto, que lo habitual era que el cuarto no proveyera mas que un espacio cerrado y en ocasiones alguna plataforma de piedra que servía de base de cama ${ }^{71}$ lo que hacía indispensable que el arriero utilizara las llamadas "camas de vientos", ${ }^{72}$ el petate, las mantas y cobijas que usaba para su propio viaje. ${ }^{73} \mathrm{Si}$ consideramos que para controlar la recua en los trayectos, además del arriero, era necesario todo un equipo de personas como lo eran el atajador, el cargador, el sabanero y los mozos; y que dependiendo de la carga se transportaba además el empaque y embalaje de los productos, ${ }^{74}$ cada habitación bien podía dar cabida a todo un equipo de transporte, sus instrumentos y aparejos.

Con esto en mente, el mesón estaba en capacidad de hospedar con comodidad hasta 168 personas, cantidad que para el último tercio del siglo xviII era considerable más no exagerada si se toma en cuenta que en 1799, tan sólo la mancha urbana de la ciudad de San Luis Potosí (sin contar los barrios extramuros de la misma) tenía una población de 6,589 personas divididas en 1,792 familias. ${ }^{75}$ Por otro lado, si consideramos que un arriero y su equipo de trabajo

${ }^{71}$ Todavía en el siglo XIX era común encontrar mesones con este tipo de cuartos. Thomas Calvo, op. cit., p. 60.

${ }^{72}$ Ibidem, p. 58.

${ }^{73}$ Sólo para el caso de huéspedes especiales se pedía prestado un colchón como ya se ha comentado en la nota correspondiente.

${ }^{74} \mathrm{El}$ atajador era el encargado de conducir a la yegua "atajadora", es decir, la que guiaba al resto de los animales. El sabanero alimentaba las bestias en las paradas; el cargador vigilaba el empaque y repartición del cargamento, y los mozos lo cuidaban. En cuanto a empaques y embalajes, éstos eran tan variados como mercancías se transportaran: costales de yute, de guancoche (para el cacao), canastas para el grano, pieles de oveja para el sebo, de cabra y cerdo para el pulque, cajones (para el mercurio), además de los aparejos (consistentes en cojines rellenos de paja) para proteger el lomo de las mulas. Thomas Calvo, op. cit., pp. 45-46.

${ }^{75}$ Archivo del Antiguo Obispado de Michoacán "Casa de Morelos”, Morelia (ААОмСм), fondo Parroquial, sección Disciplinar, serie Padrones, subserie Asientos, año 1799, caja 1340. Padrón de la feligresía de la ciudad de San Luis Potosí por el señor cura don José Anastasio Sámano para el cumplimiento de la iglesia de este año de 1799. 
(compuesto como se ha sugerido por al menos cinco personas) comúnmente se hacían cargo de una recua de entre 25 y 30 mulas, ${ }^{76}$ y que el mesón contaba con un corral de 17 metros de frente por 49 de fondo, podemos deducir que se tenía la capacidad para encerrar a más de 600 bestias, con todos los servicios garantizados, siendo el del agua el que contaba con más de una solución: además del propio pozo, brocal y piletas, se tenía la tenería de agua vecina llamada de Bollolo y en último término la corriente de agua de los Tepetates en su parte posterior.

Damos por descontado que el mesón de Fauduas no estuviera a su máxima capacidad habitualmente, lo que era seguro, era que contaba con los recursos de espacio y servicio necesarios para que un grupo regular de cinco o seis arrieros con sus respectivas 25 o 30 mulas, encontraran cobijo y lugar para resguardar sus aperos y demás pertenencias, así como sitio para el descanso de sus animales de forma garantizada.

Es probable que los dos mesones que hemos reseñado hasta aquí tuvieran una vida ya de algunos años, lo intuimos por el hecho de que existía un contrato de arrendamiento que tenía ya cierto tiempo en el caso del mesón de don Casimiro, mientras que el de Fauduas, a la muerte del dueño en 1776, estaba plenamente funcionando, y que el avalúo hecho en 1779 daba noticia de que éste se encontraba ya muy deteriorado, situación que implicaba años de descuido. Sin embargo, parece que el futuro de estos dos mesones fue efímero, ya que para 1787 (año del establecimiento de las intendencias en Nueva Espańa), el intendente Bruno Díaz de Salcedo solicitó al virrey Manuel Antonio Flores Maldonado permiso para que, en tanto se construían las Nuevas Casas Reales -cuya disposición había dejado José de Gálvez en 1767-, se pudieran "reparar las Casas Reales viejas, para convertirlas en mesón porque carece esta ciudad". ${ }^{77}$ Nuevamente sorprende la aseveración del intendente, quien era testigo de calidad para dar certeza a la realidad de que en la ciudad no se con-

${ }^{76}$ AHeslp, Alcaldía Mayor, 1755.3 (caja 590), exp. 13, ff. 8v-9r. Septiembre 6 de 1755. Lo cual coincide con lo que establece Hassing respecto a que había un arriero por cada cuatro o cinco mulas.

${ }^{77}$ AHeslp, Ayuntamiento, Actas de Cabildo, 1787, f. 51rv. Noviembre 28 de 1787. 
taba con un lugar donde los pasajeros y arrieros pudieran pernoctar. ¿Se trataba acaso de una inversión muy fuerte la que se tenía que hacer? ¿seguía funcionando -a pesar de la prohibición- la antigua práctica de algunos particulares de brindar hospedaje y corral a precios módicos? ¿seguían funcionando los mismos parajes donde pernoctar?

El que la ciudad hubiera pasado a ser el centro mismo de la intendencia más grande del virreinato, implicaba que a ésta llegarían con más asiduidad personas que ocuparían un lugar para descansar, comer y resguardar sus animales, lo cual sabía perfectamente Díaz de Salcedo, a cuya propuesta no sólo se le puede hacer una lectura bajo la visión económica, sino también formal y pragmática. Además de que era obligación de los gobernantes propiciar este tipo de servicios, como se había establecido en las Leyes de los Reinos de Indias, ${ }^{78}$ en el caso particular de los intendentes, ésta había quedado enunciada en la Real ordenanza para el establecimiento e instrucción de intendentes, la cual expresaba que

Por ser igualmente sensible a los traficantes o pasajeros la falta de posadas, y en ellas de lo necesario, deben cuidar los Intendentes-Corregidores conforme a la ley 18, título 2, libro 5, y a la 1, título 17 libro 4 de la Recopilación de Indias, de que en todos los pueblos y parajes de tránsito haya Ventas y Mesones de suficiente capacidad, con la competente provisión de víveres, camas limpias, y lo demás preciso al buen hospedaje, asistencia y alivio de los caminantes [...] Y para que se hagan Ventas y Mesones en los precisos tránsitos donde no los hubiere, informarán a la Junta Superior de Hacienda, y ésta resolverá que se construyan de los sobrantes de Propios y Arbitrios, o por medio de repartimiento entre los que recibieren el beneficio, conforme a la ley 1 , título 16 , y a la 7 , título 15 libro 4 de la misma Recopilación. ${ }^{79}$

${ }^{78}$ Supra.

${ }^{79}$ Real ordenanza para el establecimiento e instrucción de Intendentes de ejército y provincia en el Reino de la Nueva España. 1786 (introducción por Ricardo Rees Jones), México, unAm, 1984, 76-77, artículo 66. La referencia de los títulos 15 y 16 del libro cuarto de la Recopilación, tienen que ver con el hecho de que el beneficiario o los beneficiarios de la obra debían pagar por ella, repartiéndose el gasto, lo mismo que los indios, 
A la preocupación de Díaz de Salcedo la respaldaba la obligación que como intendente tenía. Acaso su intención era que con los propios de la ciudad se remozara el derruido edificio de Casas Reales para subarrendarlo a algún particular. Lo cierto es que la iniciativa del intendente no prosperó, aunque sí dejó constancia de que éste estaba al pendiente de las necesidades de la ciudad, tal y como quedó demostrado en el bando de buen gobierno que emitió en 1790, y en las ordenanzas para dividir la ciudad en cuarteles, las cuales manifestaban la necesidad de tener plenamente identificados los recintos que funcionaban como mesones, fondas, figones; $y$ que sus dueños o mayordomos debían enviar cada mañana al alcalde del cuartel, una lista de los pasajeros o huéspedes, refiriendo en ésta los nombres, compańeros o familia, procedencia y destino así como el tiempo de estancia y fecha de partida. ${ }^{80}$

San Luis Potosí mostraría un escenario diferente hacia finales del siglo XVIII y albores del XIX. La población, como ya hemos comentado ascendía a más de 6,000 almas en la zona urbana ${ }^{81}$ (la intendencia en su totalidad, a decir de Humboldt, tenía una población de 334,700 habitantes $^{82}$ ) y su comercio se había fortalecido gracias en parte a que la Intendencia había hecho que San Luis Potosí se convirtiera en el núcleo comercial de la mayor de estas divisiones administrativas. El desarrollo de la actividad agrícola en torno a cultivos como el maíz, frijol, chile, algodón, caña de azúcar, trigo, cebada, hortalizas en general, frutas e incluso viñedos, hicieron que el intercambio de estos productos (amén de los ganaderos) fuera más constante y fluido. Lo mismo había sucedido con las actividades

en cuyo caso se les repartiría lo menos que se pudiera.

${ }^{80}$ Ordenanza de la división de la muy noble ciudad de San Luis Potosi en cuarteles. Creación de los alcaldes de ellos, y reglas de su gobierno. Dada y mandada observar por el Excmo. Señor Marqués de Branciforte. Impresa en México: por don Mariano Joseph de Zúñiga y Ontiveros, calle del Espiritu Santo, año de 1796. Edición facsimilar a cargo de José Francisco Pedraza Montes, Honorable Ayuntamiento de San Luis Potosí 2000-2003, San Luis Potosí, 2001, 180rv, Art. 22 y 23. Aunque fue publicado hasta 1796, el Bando fue instruido el 15 de diciembre de 1794 (p. 184).

${ }^{81}$ Supra.

${ }^{82}$ Alejandro de Humboldt, Ensayo politico sobre el reino de la Nueva España, Instituto Cultural Helénico, tomo II, México, Miguel Ángel Porrúa, 1985, 81. 
industriales en la intendencia potosina, las cuales se habían fortalecido y aumentado sus rutas comerciales, siendo la minera, la textil, la de curtiduría y la vinícola las más importantes de ellas. ${ }^{83} \mathrm{Es} \mathrm{decir,}$ hacia el último decenio del siglo xviII, la ciudad necesitaba con más urgencia que nunca de espacios que brindaran el oportuno servicio de hospedaje, alimentación y corral.

Fue en las postrimerías del siglo xviII, y ante la certeza de la falta de un mesón, que se empezaron a edificar algunos de los más famosos que tuvo la ciudad. En 1797, José María Cortés comenzó la construcción del mesón llamado "del Platanito", en las inmediaciones de la alhóndiga, en lo que actualmente es la calle de Mier y Terán, entre las de Hidalgo y Allende.$^{84} \mathrm{La}$ construcción de este mesón se hizo en los terrenos que pertenecieron a los hermanos Bernabé de los Ángeles, Alejo Agustín Cesario y Juan José Severiano, quienes eran propietarios de la cuadra que hacía frente la alhóndiga por el costado poniente, además de un terreno de 11 varas de frente y 28 de fondo que complementaba esta propiedad. ${ }^{85}$

Por su parte, en 1798 el francés, Jerónimo Berdier (quien era un comerciante que había hecho fortuna en Real de Catorce), adquirió la antigua hacienda de beneficio de metales conocida "de Torres" 86 -apenas a un par de cuadras de la alhóndiga y colindante con los terrenos sobre los que se construyó el mesón "del Platanito"-, para fraccionarla y vender una parte por lotes ${ }^{87}$ y otra, la más importante, para convertirla en el mesón que llevaría por nombre "Santa

${ }^{83}$ Monroy Castillo, Breve historia de San Luis Potosí, p. 142.

${ }^{84}$ José Francisco Pedraza, "Los viejos mesones”, en Mensaje, vol. I, núm. 7, junio de 1966, 17.

${ }^{85}$ AHESLP, Alcaldía Mayor, 1782.2 (caja 654), exp. 43, f. 1r. Julio 27 de 1782.

${ }^{86}$ María Isabel Monroy Castillo, Sueños, tentativas y posibilidades. Extranjeros en San Luis Potosí, 1821-1845, El Colegio de San Luis, AhesLP, San Luis Potosí, 2004, 72-73.

${ }^{87}$ En los protocolos del escribano Silvestre Suárez, quedan registradas las siguientes ventas: el 15 de febrero de 1808 vendió un solar de 10 × 26 varas ubicado en la calle de la Cruz, "junto al mesón del Platanito" (AHESLP, protocolos/Silvestre Suárez, 1808, ff. 69v$71 v)$. Un día después, el 16 de febrero, vendió otro solar de 16 x 24 varas ubicado "contra esquina del mesón del Platanito" (Ibidem, ff. 71v-73v). En mayo 7 de ese mismo año, vendió dos solares, uno ubicado en la calle Nueva, junto a la hacienda de Torres y el otro junto a lo que había sido su huerta (Ibidem, ff. 166r-169v). 
Clara", ${ }^{88}$ el cual se encontraba entre las calles de Allende -conocida también como la "del francés", en honor a Berdier ${ }^{89}$-, Julián de los Reyes y Mier y Terán. Este mesón fue el más grande que tuvo la ciudad, contando para alojamiento con 38 piezas de habitación, establos, corrales, bodegas, la casa y oficina del administrador, además de la fonda que brindaba servicio tanto a huéspedes como público en general. Este mesón hubo de convertirse en el cuartel del ejército que se formó y estableció en San Luis Potosí en 1846 para combatir a los norteamericanos. ${ }^{90}$ Condición -la de cuartel- que gracias a que el siglo xIx fue un polvorín, hubo de mantener hasta 1884, lo cual sabemos por un anuncio contenido en el Almanaque Potosino de Antonio Cabrera, en el cual se informaba:

\section{iiINTERESANTE A LOS VIAJEROS!! VENTA Y MESÓN DE SANTA CLARA}

Haciendo más de dos años que esta antigua y acreditada posada ha dejado de ser cuartel, el que suscribe, actual inquilino de ella, contando con la extensión que presta su localidad, la ha montado bajo un sistema cómodo y módico para toda clase de pasajeros y transeúntes, ya particulares, arrieros o carreros, pudiendo por lo mismo ofrecerla al público como única en su género en esta plaza. Pues, además de sus corrales y cocheras y bien acondicionados macheros, de la capacidad hasta para contener quinientas bestias; sus habitaciones todas, amplias también, perfectamente ventiladas, aseadas y amuebladas, y los precios de alojamiento excesivamente baratos, se encuentra agua en abundancia, así como maiz y pasturas a precios corrientes de plaza. Condiciones en que únicamente se halla en esta ciudad la Venta y Mesón de Santa Clara, y que proporcionan al viajero toda clase de ventajas, comodidades y garantías. Más todavía: situada en las calles $2^{\mathrm{a}} \mathrm{de}$ Mier y Terán y $4^{a}$ de Allende, dista sólo de la Alhóndiga, Mercado principal, Palacio Municipal y de Gobierno, Plaza de armas, Aduana y demás edificios públicos, de una a tres cuadras.

${ }^{88}$ José Francisco Pedraza, "Litografía de ciudad antigua" (cuarta parte), en Presencia de San Luis (suplemento dominical de El Heraldo de San Luis Potosì), núm. 74, domingo 12 de agosto de $1984,2$.

${ }^{89}$ Ibidem, núm. 77, domingo 2 de septiembre de 1984, 7.

${ }^{90}$ Ibidem, núm. 74, domingo 12 de agosto de 1984, 2. 
Figura 6. Mesón de Santa Clara a principios del siglo xx. Fotografía de libre circulación

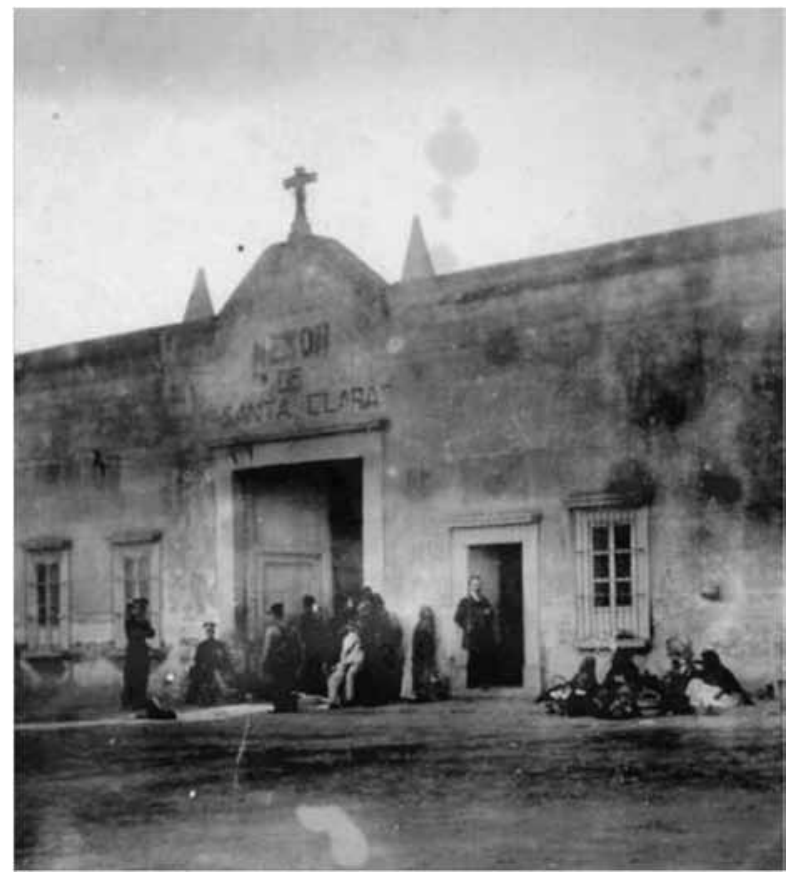

Contando también con inteligente servidumbre y magníficos veterinarios, se reciben a precios convencionales caballos y carruajes a pensión, así como comisiones de compra y venta de animales.

Manuel F. Tolentino. ${ }^{91}$

Poco duraría su "libertad", ya que en 1915, durante la Revolución, el mesón volvió a convertirse en cuartel (figura 6), ahora de villistas y después de carrancistas. ${ }^{92}$ Interesa de la descripción hecha por el Sr. Tolentino el que se resalte el tipo de huésped básico para el

${ }^{91}$ Antonio Cabrera, Almanaque potosino, sección de anuncios, año 1, San Luis Potosí, 1886, 7. Pedraza la reproduce también en su "Litografía de ciudad antigua".

${ }^{92}$ José Francisco Pedraza, "Litografía de ciudad antigua”, Presencia de San Luis, núm. 74,12 de agosto de $1984, .2$. 
Figura 7. Plano de la ciudad de San Luis Potosí levantado por el profesor de farmacia, Florencio Cabrera, 1869 (fragmento). En torno a la alhóndiga el mesón del Platanito, el de la Sirena, el de Santa Clara y la calle del mesón del Refugio. Fondo: Mapas y planos de la Biblioteca "Rafael Montejano y Aguiñaga", El Colegio de San Luis

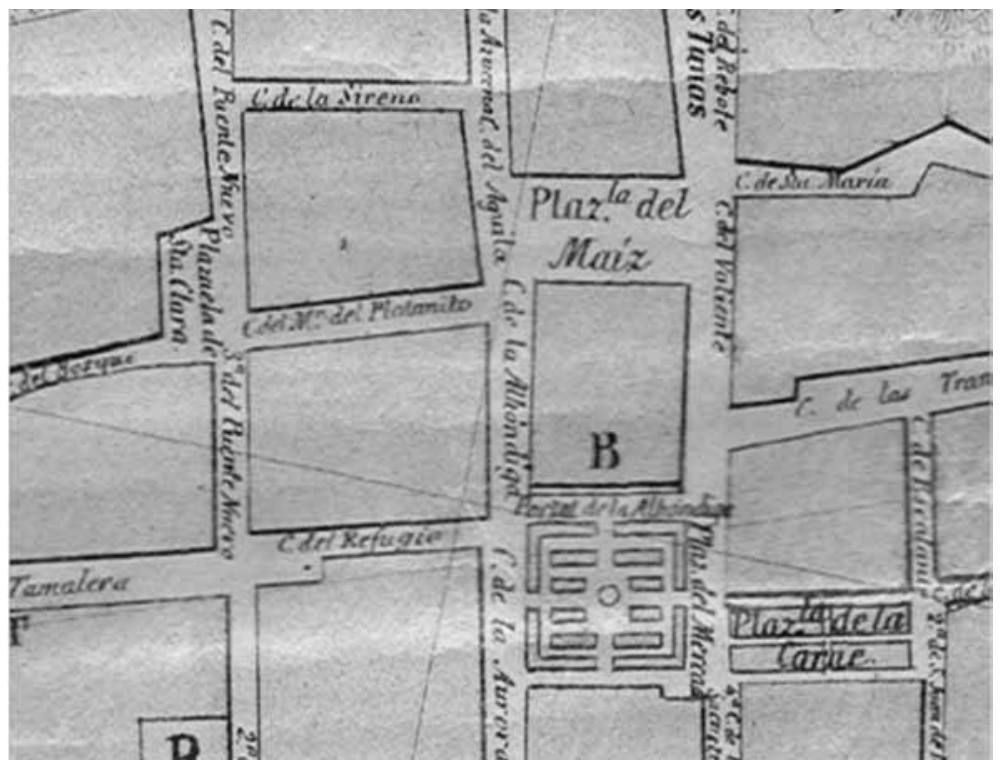

cual estaba diseñado el mesón: el arriero y sus bestias. Finalmente, no podemos soslayar tampoco el hecho de que este tipo de edificaciones fueron, por logística y practicidad, los sitios idóneos para albergar a la tropa cuando ésta pasaba o se acantonaba por la ciudad; así lo había demostrado Gitart con su queja en 1775 y así quedaba en claro en la historia del mesón de Santa Clara.

A estos mesones se les sumaría el llamado mesón de la "Sirena", construido también a finales del siglo xviII, y que dio el nombre antiguo a dicha calle -hoy Alcalde- y que al igual que los dos anteriores se ubicaba cerca el núcleo comercial que era la alhóndiga, sobreviviendo hasta la época de la Revolución. 
En un plano de la ciudad de San Luis Potosí de 1869, encontramos la referencia de estos tres mesones (figura 7); el primero ubicado en la calle de la Sirena, donde se desplataba el mesón del mismo nombre, y junto a éste, hacia el sur, la calle del mesón del Platanito (hoy Mier y Terán), en tanto que el mesón de Santa Clara, se señaló por medio de la "plazuela de Santa Clara", en lo que ahora es la calle de Mier y Terán y Allende. Es decir, a principios del siglo XIX y durante toda esta centuria, en torno a la alhóndiga se empezaron a construir mesones, y aun cuando la alhóndiga había perdido en 1827 su función de almacén, centro de distribución y venta de granos, la zona y sus inmediaciones se habían convertido ya en una célula urbana de febril actividad comercial donde el trajín del comercio y los negocios, y la abundancia de comerciantes con sus recuas, carretas y carretones provenientes de diferentes latitudes, ocupaban un lugar para pernoctar, comer y guarecer sus bestias. La referencia publicitaria del mesón de Santa Clara el cual según se anunciaba estaba a una cuadra de la alhóndiga, consolida la idea de que ésta se había convertido en el núcleo fundamental de la vida económica de la ciudad y, en consecuencia, destino obligatorio de los viajeros y lugar idóneo para los mesones.

Ya en pleno siglo XIX, cuando los mesones abundaban en la ciudad, el general Miguel Miramón decretó, el 11 de octubre de 1858, la demolición del "mesón del Refugio", propiedad de Hilario Delgado, el cual se ubicaba en el trayecto necesario para ampliar y abrir una calle a un costado de la iglesia de la Compañía, que llevaría el nombre de Ahualulco (actualmente Damián Carmona), en honor a la batalla que este militar le había ganado a Vidaurri en Ahualulco el 29 de septiembre de ese año. El citado mesón se encontraba aproximadamente entre las actuales calles de Arista y Julián de los Reyes -a la altura de la alhóndiga-, por lo que proveía hospedaje a los viajeros que venían del norte. En 1867, tras diez años de litigio (éste duraría casi 20), Hilario Delgado solicitó como indemnización -por el daño causado a su mesón- el derecho de fabricar altos en los techos de la alhóndiga, construyendo escaleras en los cuatro callejones del edificio y teniendo las servidumbres de agua y la de entrada y salida por las puertas principales, estimando los costos en 20,000 pesos. El 
gobernador Juan Bustamante nombró una comisión compuesta por P. R. Gordoa, Francisco P. Palomo y Eulalio Degollado, para que se analizara esta petición, la cual fue aceptada en un principio poniéndose por obligación el construir inmediatamente los altos del edificio por ser "una obra de embellecimiento y ornato público"; sin embargo, a la postre tal recomendación fue desechada por el propio gobernador Bustamante. ${ }^{93}$

Otros mesones abundaban por aquellas épocas. Completan el panorama "el mesón de la Lagunita", donde posteriormente se construyó una plaza de gallos, ${ }^{94}$ entre lo que son la plazuela de San Francisco y la iglesia de San Agustín. El "Mesón del Venadito” y el "Mesón de Belén", cercanos al Eje Vial; por el rumbo del Barrio de San Sebastián el "Mesón de Santillán”, justo en el callejón del mismo nombre y que hacia 1960 fue el último en cerrar sus puertas en la ciudad;" el "Mesón de San Agustín, que se encontraba en la actual calle de Universidad, entre 5 de mayo y Zaragoza; el "Mesón de San Joaquín", en la hoy calle de Madero; el de "Marmolejo", por la plazuela de la Merced, y el "Mesón de San Ignacio", cercano a la alhóndiga, por la calle de Insurgentes. ${ }^{96} \mathrm{El}$ de "San Antonio", en la actual calle de Madero, entre Bolívar e Independencia; el de "Gordoa”, en la hoy calle de Uresti, entre Carranza y Arista; y el mesón de "San José", ubicado estratégicamente donde convergían los antiguos caminos de Guanajuato y México, justo enfrente de la garita de México, ${ }^{97}$ donde necesariamente tenían que cruzar los viajeros provenientes de aquellas regiones.

${ }_{93}^{3}$ Julio Betancourt, "La Alhóndiga", en Periódico Oficial del Gobierno del Estado Libre y Soberano de San Luis Potosí, tomo XL, núm. 41, San Luis Potosí, 29 de mayo de 1914, 10; y Rafael Montejano y Aguińaga, "La Alhóndiga" (artículo transcrito y comentado por Rafael Montejano y Aguiñaga del original de Julio Betancourt en el Periódico Oficial del Estado), en Archivos de Historia Potosina, vol. 1, núm. 4, abril-junio, 1970, 277 y 279.

${ }^{94}$ Manuel Muro, Miscelánea potosina. Biografias, artículos históricos y de costumbres, tradiciones y leyendas, Tipografía de la Escuela Industrial Militar, San Luis Potosí, 1903, 180.

${ }^{95}$ José Francisco Pedraza, "Los viejos mesones" ..., p. 17.

${ }^{96}$ Idem.

${ }^{97}$ Plano de la ciudad de San Luis Potosi levantado por el profesor de farmacia Florencio Cabrera, 1869. Fondo de mapas y planos, Biblioteca "Rafael Montejano y Aguińaga", El Colegio de San Luis. 
A estos mesones se suman de nombre, no así de exacta ubicación, el "Mesón del Ángel”, el de "Dolores”, el "de Milán”, el "de la Providencia”, el "de Rocha”, el "Mesón de Santa Gertrudis y el "de la Mulita".

Los mesones se complementaban con las posadas, las cuales florecieron también por aquellos años, como la denominada "posada del Rastro", nombrada así porque en sus instalaciones había funcionado el rastro hacia $1831,{ }^{98}$ aunque en este caso, dicho establecimiento sólo ofrecía el servicio de alojamiento de personas.

¿Qué propició que en San Luis Potosí no se tengan noticias precisas acerca de los mesones durante la época virreinal? Aunque la información es poca, resulta recurrente la mención de que "no hay mesón" en la ciudad, menos cuando ésta era aún pueblo. No obstante, poco a poco va surgiendo información en los archivos locales (este trabajo es una prueba de ello), y, sin embargo, no podemos dejar de lado el hecho de que aun y cuando hemos rescatado del olvido dos mesones del siglo XVIII, la cantidad resulta muy pobre para una ciudad tan grande y tan importante. ${ }^{99}$ Acaso las viejas prácticas seguían vigentes y los mesones simplemente no eran una tipología que urgiera, o bien se trató de un negocio que implicaba una fuerte inversión y una lenta -y a veces poco probable- recuperación de ésta, dejando a los arrieros y carreteros de la "garganta de la tierra adentro", sin un lugar formal para pernoctar. Lo cierto es que tarde -ya en el siglo XIX- y al igual que en el resto de México, estos tuvieron un auge muy importante.

La construcción de una nueva alhóndiga en el año de 1771 parece ser que fue el detonante para que los mesones empezaran a consolidarse en la escena urbana de la ciudad, al menos los dos que referimos aquí estaban ligados al alojamiento de arrieros. Poco a poco, en torno al núcleo comercial que se gestó en los alrededores del depósito de granos, fueron apareciendo -ahora sí en grandes cantidades- complejos arquitectónicos que brindaban hospedaje,

${ }^{98}$ Manuel Muro, Historia de San Luis Potosí, por Manuel Muro, miembro honorario de la Sociedad Mexicana de Geografía y Estadistica..., tomo II, Imp. Moderna de Fernando H. González, 5 de Mayo y Fuente, Esquina, San Luis Potosí, 1910, 7.

${ }^{99}$ En comparación, existieron al menos cuatro mesones en Zacatecas en la segunda mitad del siglo XVIII. Carrillo Acosta, op. cit., p. 80. 
resguardo, aseo y diversión. Fue así que los mesones se fueron conjuntando en una zona que era ya un circuito comercial perfectamente establecido - con la alhóndiga como centro rector-, donde las plazuelas, los mercados, los tendajones y cocinas improvisadas, el juego de pelota, los albures, los juegos de azar y las pulquerías, ofrecían al arriero, al comerciante, al visitante casual o al interesado, la oportunidad de la agitada vida que surgía cuando las actividades mercantiles se desvanecían y traslapaban con las de la aventura y el placer. Escenarios donde también el vecino de la ciudad encontraba la novedad y el "chisme" traídos por los viajeros foráneos, espacio para apuntalar negocios al calor de la liba, o donde entre el canto, el baile y el juego se podían encontrar amores de una noche. Era el mesón y sus alrededores, el espacio donde el interdicto no hacía menos común su trasgresión.

Pero más que nada, fueron los mesones el lugar para que los viajeros y los arrieros reposaran y pernoctaran, para que las bestias cansadas y trasudadas encontraran agua, comida y aliento; sitios en los que, entre el olor de forraje y bestias, y el amontonamiento de las mercancías estibadas, se vivía una vida que sólo el comerciante viajero conocía y a la cual nosotros sólo podemos acceder tratando de construir la historia de aquellos locales que les servían de morada transitoria.

La historia de los mesones, sin embargo esquiva, sigue dándosenos a cuenta gotas, ayudándonos a construir de a poco la historia de los espacios de alojamiento en el San Luis Potosí virreinal.

\section{FUENTES DOCUMENTALES Y BIBLIOGRÁFICAS}

Archivo General de la Nación (AGN).

Real Audiencia, Indios, vol. 5, exp. 14.

Archivo Histórico del Estado de San Luis Potosí (AHESLP).

Fondos:

Ayuntamiento, 1763-1769, 1787.

Alcaldía Mayor, 1623.3, 1636.5, 1655.3, 1676.2, 1721, 1750.1, 1764.1, 1775.2, 1776.1, 1776.2, 1779.3, 1782.2, 1784.2, 1794.3. 
Archivo del Antiguo Obispado de Michoacán "Casa de Morelos" (AAOMCM).

Fondo: Parroquial; sección: Disciplinar; serie: Padrones; subserie: Asientos; año: 1799; caja: 1340. Padrón de la feligresía de la ciudad de San Luis Potosi por el señor cura don José Anastasio Sámano para el cumplimiento de la iglesia de este año de 1799.

Mapas y planos de la Biblioteca "Rafael Montejano y Aguiñaga" de El Colegio de San Luis.

\section{BibLIOGRAFÍA}

Arnal Simón, Luis, El presidio en México en el siglo XVI, Facultad de Arquitectura, unam, México, 1998.

Betancourt, Julio, "La Alhóndiga", en Periódico Oficial del Gobierno del Estado Libre y Soberano de San Luis Potosí, tomo xL, núm. 41, San Luis Potosí, 29 de mayo de 1914, 9-10.

Cabrera, Antonio, Almanaque potosino, año 1, San Luis Potosí, 1886.

Calvo, Thomas, Por los caminos de Nueva Galicia. Transportes y transportistas en el siglo XVII, México, Universidad de Guadalajara, Centre Français D'Études Mexicaines et Centraméricaines, 1997.

Carmona Rodríguez, Josefa, La alhóndiga malagueña: arquitectura y urbanismo, Málaga, Diputación Provincial de Málaga, Biblioteca Popular Malagueña, 77, 1997.

Carrillo Acosta, Roberto, El papel de los mesones en Zacatecas. El mesón de Tacuba durante los siglos XVIII y XIX, tesis de grado de Maestría en Historia, UAZ, Zacatecas, 2008.

Cramaussel, Chantal, Poblar la frontera. La provincia de Santa Bárbara en Nueva Vizcaya durante los siglos XVI y XVII, El Colegio de Michoacán, México, 2006.

,"El camino real de tierra adentro. De México a Santa Fe", en Chantal Cramaussel, ed., Rutas de la Nueva España, El Colegio de Michoacán, México, 2006, 299-327.

Chávez Orozco, Luis, Alhóndigas y pósitos, México, ANDSA, 1966. FloresCANo, Enrique, "El abasto y la legislación de granos en el siglo xvI", en Historia Mexicana, vol. xIv, abril-junio de 1965, 567-630. 
García López, José Ricardo, Guia de instrumentos públicos. 18051810 (Protocolo del escribano público Silvestre Suárez y su teniente Antonio María Suárez), San Luis Potosí, Facultad de Derecho de la UASLP, Gobierno del Estado de San Luis Potosí, 2008.

Guthrie, Chester L., "Trade, Industry, and Labor in Seventeenth Century Mexico City", en Revista de Historia de América, núm. 7, diciembre de 1939, Instituto Panamericano de Geografía e Historia (oEA), 1939, 103-134.

Gutiérrez Cantú, Luis Pedro, La provincia de los llanos. Charcas 1550 a 1610, Copocyt, Conaculta, Patronato para el fomento cultural de Charcas, México, 2005.

Hassing, Ross, Comercio, tributo y transportes. La economía política en el valle de México en el siglo XVI, México, Alianza Editorial Mexicana, 1990.

Humboldt, Alejandro de, Ensayo político sobre el reino de la Nueva España, 4 tomos, México, Instituto Cultural Helénico, Miguel Ángel Porrúa, 1985.

Izquierdo Benito, Ricardo, “Toledo en 1492”, en Pedro Miguel Ibáńez, coord., Memoria del Nuevo Mundo. Castilla-La Mancha y América en el quinto centenario, Universidad de Castilla-La Mancha, 1992, 51-70.

López Martínez, Celestino, Mudéjares y moriscos sevillanos, Sevilla, Ed. Renacimiento, 1994.

Martínez, José Luis, Pasajeros de Indias. viajes trasatlánticos en el siglo XVI, 2a reimpresión, México, Alianza (Universidad), 1997.

Martínez Rosales, Alfonso, El gran teatro de un pequeño mundo. El Carmen de San Luis Potosi, 1732-1859, El Colegio de México, Universidad Autónoma de San Luis Potosí, México, 1985.

Monroy Castillo, Isabel y Tomás Calvillo Unna, Breve historia de San Luis Potosí, México, FCE, El Colegio de México, 2000.

Monroy Castillo, María Isabel, Sueños, tentativas y posibilidades. Extranjeros en San Luis Potosí, 1821-1845, San Luis Potosí, El Colegio de San Luis, AHESLP, 2004.

Montejano y AguiÑaga, Rafael, "La Alhóndiga" (artículo transcrito y comentado por Rafael Montejano y Aguińaga del original de Julio Betancourt en el Periódico Oficial del Estado), en 
Archivos de Historia Potosina, vol. 1, núm. 4, abril-junio, 1970, 274-279.

Muro, Manuel, Miscelánea potosina. Biografias, artículos históricos y de costumbres, tradiciones y leyendas, San Luis Potosí, Tipografía de la Escuela Industrial Militar, 1903.

, Historia de San Luis Potosi, por Manuel Muro, miembro honorario de la Sociedad Mexicana de Geografia y Estadistica, precedida de un juicio crítico escrito por el Sr. licenciado D. Emilio Ordaz, San Luis Potosí, Imp. Moderna de Fernando H. González, 5 de Mayo y Fuente, Esquina, 1910, 3 tomos.

Ordenanza de la división de la muy noble ciudad de San Luis Potosi en cuarteles. Creación de los alcaldes de ellos, y reglas de su gobierno. Dada y mandada observar por el Excmo. Señor Marqués de Branciforte. Impresa en México: por don Mariano Joseph de Zúniga y Ontiveros, calle del Espiritu Santo, año de 1796. Edición facsimilar a cargo de José Francisco Pedraza Montes, San Luis Potosí, Honorable Ayuntamiento de San Luis Potosí 2000-2003, 2001.

Pedraza, José Francisco, "Los viejos mesones”, en Mensaje, vol. I, núm. 7, junio de 1966, 17.

, "Litografía de ciudad antigua" (cuarta parte), en Presencia de San Luis (suplemento dominical de El Heraldo de San Luis Potosi), núm. 74, domingo 12 de agosto de 1984, 2.

"Litografía de ciudad antigua" (séptima parte), en Presencia de San Luis (suplemento dominical de El Heraldo de San Luis Potosi), núm. 77, domingo 2 de septiembre de 1984, 7.

Real ordenanza para el establecimiento e instrucción de Intendentes de ejército y provincia en el Reino de la Nueva España. 1786, introducción por Ricardo Rees Jones, México, UNAM, 1984.

Recopilación de Leyes de los reinos de las Indias, 1681, 5 tomos, Edición facsimilar Conmemorativa al v Centenario del Descubrimiento de América en el Lxxv Aniversario de la Escuela Libre de Derecho, Miguel Ángel Porrúa y Escuela Libre de Derecho, México, 1987.

Reyes, Aurelio de los, Los caminos de la plata, México, Gobierno del Estado de Zacatecas, Patronato de Minería Cinco Siglos en México, Universidad Iberoamericana, 1991. 
Sarabia Viejo, María Justina, "Los caminos del Golfo de México", en Chantal Cramaussel, ed., Rutas de la Nueva España, Zamora, El Colegio de Michoacán, 2006, 97-115.

Valle Pavón, Guillermina del, "La economía novohispana y los caminos de la Veracruz y Orizaba en el siglo Xvi", en Chantal Cramaussel, ed., Rutas de la Nueva España, El Colegio de Michoacán, México, 2006, 39-61.

Venegas Ramírez, Carmen, Régimen hospitalario para indios en la Nueva España, México, INAH, SEP, 1973.

FECHA DE RECEPCIÓN DEL ARTículo: 3 de octubre de 2011

FECHA DE ACEPTACIÓN Y RECEPCIÓN DE LA VERSIÓN FINAL: 22 de febrero de 2012 